\title{
Desigualdades territoriales en México derivadas del tratado de libre comercio de América del Norte
}

\begin{abstract}
The coming into force of the North American Free Trade Agreement (NAFTA) from 1994 consolidated a phase of Mexican economic liberalization that had begun in 1982. The systematic operationalization of the NAFTA in different sectors of the economy (incorporated into this commercial agreement) was also accompanied by favorable spatial impacts in some cases, and unfavorable impacts for a significant number of regions and states of the Mexican federation. Fourteen years on, this article analyzes the processes of spatial restructuring that have been generated, the regional disparities associated with the new international scenario, and explains the economic relations that run in opposition to the current stage of the dominant neoliberal model, which has excluded other traditional forms of organization and has kept many areas of Mexico in a condition of social marginalization.
\end{abstract}

Key words: regional development, economic globalization, free trade agreement, social polarization and spatial inequality.

\section{Resumen}

La instrumentación del Tratado de Libre Comercio de América del Norte (TLCAN) a partir del año 1994 consolidó una etapa de liberalización económica iniciada en México a partir de 1982. La sistemática operación del TLCAN en los distintos sectores de la economía (incorporados a este acuerdo comercial) se vio al mismo tiempo acompañada de efectos territoriales favorables en algunos casos, y de dimensiones críticas para un número importante de regiones y estados que componen la federación mexicana. Después de 14 años de su inicio, en este trabajo se analizan los procesos de reestructuración espacial desde entonces generados, las disparidades regionales asociadas al nuevo escenario internacional, y se da cuenta de las relaciones económicas que contraponen a la etapa actual del modelo neoliberal imperante con aquellas otras formas tradicionales de organización excluidas y que aún mantienen en México buena proporción de espacios socialmente marginados.

Palabras clave: desarrollo regional, globalización económica, tratado de libre comercio, organización territorial, polarización social y desigualdades espaciales. 


\section{Introducción}

C on la globalización se produce un redimensionamiento de las relaciones entre las regiones, el Estado y la sociedad. La globalidad afecta de distintas maneras la unidad del Estado nacional y de la sociedad en su entorno regional y local; Incluso se ha dicho en extremo que este proceso empuja la desaparición del Estado nacional (Ohmae, 1990). Se establecen nuevos vínculos de poder y se convoca a la competitividad como el vigoroso instrumento del "nuevo desarrollo"; conflictos y entrecruzamientos entre, por una parte, unidades y actores del mismo Estado nacional, y por otra, situaciones, procesos y espacios sociales transnacionales (Ferrer, 1996; Iani, 1999; Chomsky y Dieterich, 1999; García Canclini, 2000; Alonso Aguilar, 2002). No obstante, no se puede afirmar categóricamente la existencia generalizada de un espacio global, sino de espacios subnacionales de la economía internacional (Bervejillo, 1995; Benko y Lipietz, 2000; De Mattos, 2005). En este sentido emerge un esquema de producción mundial a través de la descentralización o externalización de procesos productivos en un gran número de países, lo cual rompe con los patrones clásicos de localización de las actividades productivas y se recrean nuevas modalidades de las geoeconomías mundiales, los sistemas-red y las geografías nacionales (Gatto, 1999; Castells, 2000; Molero, 2001; Alburquerque, 2004; Méndez, 2006).

* Doctor en Geografía e investigador titular del Instituto de Investigaciones Económicas de la Universidad Nacional Autónoma de México (UNAM). E-mail: jdm@servidor. unam.mx.

* El artículo es producto de la estancia académica que el autor realiza en el Instituto de Desarrollo Regional, Fundación Universitaria, de Sevilla, España, institución a la que agradece las facilidades prestadas.

1 Incluso en el ámbito de la ciencia económica predominante y en palabras de expertos de otras disciplinas administrativas, de escuelas de negocios, empresariales, y prácticamente de todas partes, y como lo referencia Capello (2006 p. 186), “...han elevado a la "competitividad" a un status de ley natural de la moderna economía capitalista”. Véase también al respecto Kitson et. al., 2005.

Recibido el 22 de enero de 2007

Aceptado el 24 de abril de 2007
Sin embargo, también la globalización genera efectos desiguales sobre el territorio, situación que desde el ámbito del análisis regional plantea nuevas incógnitas sobre la permanencia o coexistencia de regiones y sistemas urbanos de tipo tradicional, frente a fenómenos territoriales emergentes a partir de las nuevas relaciones internacionales. La medición y explicación de estos contrastes confronta también a los especialistas en esta materia, según lo expone Simmies (1997, citado por Boisier, 2000), ya que se tiende a agruparse entre aquellos preocupados por los papeles cada vez más significativos desempeñados por las grandes corporaciones y aquellos interesados en las empresas más pequeñas, y ambos con las causas de la aglomeración espacial de las actividades económicas innovadoras; es decir, el tamaño de la globalidad infiere procesos y efectos territoriales distintos. ${ }^{2}$

Por otra parte, y en contraste con los efectos macro de la globalización, se manifiestan nuevas formas de reestructuración territorial al interior de los países y de manera más intensa en los países subdesarrollados. Como lo expresa Andreas Hildenbrand (2006), la fuerte suburbanización expandida a nivel global desde la década de los 80 ha tenido consecuencias importantes en la reorganización de los territorios subnacionales; se ha producido una ampliación de la escala geográfica de la acción pública local (y de los actores regionales), ya que un número cada vez mayor de asuntos municipales rebasan los límites administrativos propios y tienen que ser atendidos en un marco de políticas públicas locales-regionales, tales son los ejemplos de la necesaria gobernanza metropolitana en las grandes ciudades. De estos nuevos fenómenos espaciales deriva la necesidad

\footnotetext{
2 Sergio Boisier (2000) sintetiza bien los argumentos de uno y otro lado: Un lado argumentativo es sostenido por autores como Froebel, Heinrichs y Kreye, Henderson y Castells, Amín y Robins, y sugiere que ha surgido una economía global dominada por grandes corporaciones trasnacionales donde las decisiones de dónde ubicar actividades como las productivas o de investigación y desarrollo determinan en gran medida qué tipo de actividad económica se aglomera en qué lugar; así el territorio se transforma en una suerte de "variable dependiente" en la función de crecimiento innovador. Del otro lado del argumento (Piore y Sabel, Porter, Alburquerque, Scott y Storper, Stöhr, Vázquez Barquero, Garofoli, Cuadrado-Roura y Boisier) se señala que los lugares, territorios, comunidades y/o localidades están siendo más, y no menos importantes en su contribución a la innovación y a la tecnología.
} 
de la cooperación como categoría territorial propia del ámbito local-territorial.

Estos contrastes son aún más marcados en México, al observar que su desarrollo regional se ha expresado históricamente en distorsiones territoriales que son producto de una excesiva concentración económica, centralidad de las decisiones políticas y desigual distribución de los beneficios (Carmona, 1999; Bassols, 1999; Messmacher, 2000; Calva, 2005; Delgadillo, 2006). Esta diferenciación espacial se hizo más evidente mediante la ubicación geográfica del aparato productivo, la inequitativa distribución regional del ingreso y la calidad de vida de la población, elementos que favorecieron a diferentes porciones del centro y el norte del país, quedando marginados el sur y el sureste. Pareciera entonces que el fenómeno histórico de polarización se acentúa con la apertura comercial (como expresión de la globalización), que se expresa progresivamente a partir del año 1984 y con gran intensidad hasta nuestros días, y produce además en los ámbitos locales fragmentaciones entre grupos sociales y espacios geográficos determinados, como son las zonas rurales del país y los cinturones de pobreza urbana cada vez más extendidos en las grandes ciudades.

\section{Antecedentes}

Desde mediados del siglo XX la dinámica de la economía mexicana ya manifestaba una clara relación en términos de los intereses de Estados Unidos en el interior del país, como en los procesos de inversión en la agricultura, la minería y el comercio binacional. Durante la segunda guerra mundial y hasta mediados de los años sesenta se establecieron acuerdos migratorios que permitían la incorporación de trabajadores mexicanos al campo y la industria estadounidense. Más recientemente, el desarrollo de plantas maquiladoras, la ampliación de los intercambios comerciales y la aplicación de distintos programas de cooperación habían intensificado las relaciones binacionales y transfronterizas. Se puede constatar que incluso varios años antes del inicio formal del Tratado de Libre Comercio de América del Norte que signaron México, Canadá y Estados Unidos (TLCAN) ${ }^{3}$,

El TLCAN, también conocido como NAFTA por se había iniciado un proceso de apertura de la economía y, con ello, se lograron intensificar las relaciones económicas, particularmente con los Estados Unidos: en 1986 México se incorpora al Acuerdo General de Aranceles y Comercio (GATT, por sus siglas en inglés), fecha en la que se registra una progresiva disminución de sus cuotas arancelarias y la operación sistemática de procesos de desregulación financiera, energética, y especialmente en el renglón de inversiones foráneas; en 1993 ingresa al grupo de Cooperación Económica del Asia Pacífico (APEC por sus siglas en inglés) y con ello se reafirma la decidida determinación del libre comercio global y sería este el preámbulo a la firma del más importante acuerdo comercial, el TLCAN. Antes de este tratado, México ya había suscrito en 1992 un acuerdo comercial con Chile y en 1994 consolida su posición internacional al ser aceptado dentro del selecto grupo de la Organización para la Cooperación y el Desarrollo Económico, OCDE. $\mathrm{Al}$ año 2007 son 26 los acuerdos pactados con diversos países y regiones del mundo (Secretaría de Economía, 2007).

Una década antes de iniciado el TLCAN se opta por una clara adopción de un modelo económico de rasgos exógenos que significó a la larga un cambio cualitativo en los procesos y espacios de acumulación de capital. Esto se constata a partir de la reorientación de los circuitos de inversión y los procesos de reestructuración industrial que se implementaron en prácticamente todas las ciudades del país (Wong, 1997; Delgadillo, 2001; Villarreal, 2002). La transición de un modelo territorial incipientemente endógeno a uno de características trasnacionales derivó en la revaloración de algunos espacios no tradicionales y la emergencia de nuevas regiones y ciudades. En este nuevo esquema los puertos marítimos, las

sus siglas en inglés, es un acuerdo regional entre los gobiernos de Canadá, México y Estados Unidos signado en enero de 1994, con la finalidad de crear una amplia zona de libre comercio; la implementación de este tratado promueve la apertura de sus fronteras de manera paulatina (y con mayor afectación para México en su sector agropecuario, a partir del año 2005). Entre otros, "sus objetivos se centran en eliminar obstáculos al comercio y facilitar la circulación transfronteriza de bienes y servicios, respetar la competencia leal, aumentar sustancialmente las oportunidades de inversión y proteger y hacer valer los derechos de propiedad intelectual" (www. nafta-sec-alena.org/DefaultSite/index_e.aspx). 
regiones fronterizas del norte mexicano y diversas ciudades de rango medio en el centro y norte del país se volvieron atractivas a las nuevas estrategias de expansión de los capitales foráneos en territorio nacional. Esta reactivación de regiones y ciudades, diferentes a los centros tradicionales, era posible porque representaban lugares donde se podrían implantar estrategias productivas compartidas con las empresas matrices en Estados Unidos o se utilizarían como espacios alternativos para establecer y/o ampliar las plataformas productivoexportadoras. Este ha sido el caso de las ensambladoras automotrices, los distritos industriales de autopartes y los nuevos parques maquiladores de la electrónica, entre otros, procesos que a través de los acuerdos comerciales han sido comunes a diversos países latinoamericanos (CAF, 2005).

Ante esta dinámica de reestructuración económica y territorial, un tema discutido antes de la entrada en vigor del TLCAN fue el del posible impacto que tendría este acuerdo comercial en las condiciones sociales, los efectos ambientales, y de manera particular, en los ámbitos urbano-regionales. A la luz de ello, se discutieron también las dimensiones sectoriales y de las actividades abiertas a la integración, surgieron controversias (Leycegui, 2000) y se elaboraron escenarios sobre el impacto diferenciado de este acuerdo comercial en las distintas regiones y ciudades mexicanas (Federal Reserve Bank of Dallas, 2005). Más adelante se formularon modelos de impacto, análisis de competitividad regional y otros estudios específicos sobre tendencias locacionales de sectores productivos (Gruben, 2001; Gereffi, 2002); se llevaron a cabo ejercicios para determinar el grado de convergencia y polarización (Carrillo, 2001; Pose, 2002; Ornelas, 2004; Aguayo, 2006). Todo ello con la finalidad de conocer las debilidades y fortalezas de las entidades federativas y las ciudades mexicanas, así como para documentar, en términos de previsión, los posibles procesos de reestructuración urbano-regional bajo un contexto de mayor apertura económica. Desde entonces diversos investigadores, centros e instituciones abordaron el debate sobre las regiones y sectores "ganadores" y "perdedores" (Dussel, 2003; Ruiz Durán, 2004; Federal Reserve Bank of Dallas, 2005).

A la luz de los resultados ampliamente documentados y una vez que México se apresta en
2007 a enfrentar con mayor crudeza la apertura total de su sector agrícola, en el presente texto se plantean las siguientes hipótesis: a) la primera fase del TLCAN ha generado en el interior del país un incremento de las asimetrías económicas entre entidades federativas tradicionalmente rezagadas, respecto de aquellas que ya mostraban cierta consolidación en el marco de la integración regional mexicana; b) junto a ello, se mantiene, y en algunas regiones se incrementa, la polarización territorial medida en términos de población y desigualdad social; c) y se produce una acentuación del proceso de divergencia regional ya presente desde inicios de los años ochenta.

\section{Apertura comercial e indicadores económicos}

Se reconoce que el TLCAN es el tratado más importante en materia de comercio en la historia de los tres países que lo integran (Ortiz et. al., 1998). Su operación se enmarca dentro de las excepciones que establece el GATT, que permite a dos o más Estados otorgarse recíprocas concesiones comerciales sin tener que hacerlas extensivas al resto de los países parte. En ese sentido, el TLCAN crea una zona de libre comercio, primer paso dentro de los niveles de integración económica, aunque en realidad en el TLCAN se incorporan algunos elementos o características propias de niveles de integración más avanzados, como son, de acuerdo con Patiño (1993), la eliminación de restricciones a la libre circulación de factores productivos diversos a las mercancías, como el comercio de servicios, de capitales y la tecnología, la armonización de ciertas políticas económicas y la solución de controversias con decisiones obligatorias para los miembros.

Antes y después de su aplicación se han manifestado opiniones críticas sobre los efectos que dicho acuerdo traería en sectores económicos, en factores sociales del desarrollo y en temas ambientales. Si bien la adopción de este Tratado como propuesta de reactivación de la economía mexicana y la adaptación de ésta a los procesos de cambio económico mundial no contemplaron como objetivo un mejoramiento específico de los desequilibrios regionales internos, sí consideraron, como contraparte, un proceso dinámico 
de las actividades económicas que, de acuerdo con su inercia, generaría impactos territoriales en aquellas regiones que el modelo de economía protegida había marginado del desarrollo por fallas en la planeación y en la canalización de las inversiones gubernamentales. Se adoptó la inversión extranjera directa (IED) como el instrumento de reactivación, pero sus efectos positivos habría que buscarlos, hasta ahora, en el nivel sectorial y no en el regional, aunque algunos estados del país presentan una relativa mejoría debido a la incorporación de determinados nichos territoriales a esta nueva dinámica de economía abierta.

En el momento actual el tamaño de la economía mexicana, medida en términos del Producto Interno Bruto (PIB), es equivalente a la de países como España, Corea del Sur o Canadá. De acuerdo con información oficial para el año 2005 alcanzó la cifra de 814 mil 860 millones de dólares internacionales a precios corrientes, mientras que la IED para el mismo año registró un valor de 18 mil 934 millones de dólares (equivalente al 2.3\% del valor del PIB nacional). Su contribución a la economía mexicana ha sido compleja y ambigua (Dussel, 2000); se presenta como un factor importante para alcanzar una relativa estabilidad en algunas variables macroeconómicas y también como soporte a las estrategias de desarrollo iniciadas en 1988. En otro sentido favorece la modernización de la economía por la vía de las empresas extranjeras asentadas en territorio nacional que han realizado asociaciones y fusiones con capital nacional. Sin embargo, la IED no ha logrado resolver los principales retos de la economía mexicana: encadenamientos e integración productiva regional, empleo, financiamiento y sustentabilidad económica a mediano y largo plazo.

Desde una perspectiva macroeconómica, la IED es la principal fuente de financiamiento de la nueva estrategia de desarrollo y se ha convertido en uno de los más importantes factores que permiten la modernización económica y la orientación exportadora de un segmento del sector manufacturero. Debido a que constituye uno de los factores para financiar el desarrollo de la economía mexicana y adecuarla a los niveles de competitividad que requiere la dinámica de una economía abierta, a partir del TLCAN el gobierno se convirtió en el principal promotor para desregular la inversión extranjera a nivel internacional y vincularla con el comercio. Lo anterior implica un alto grado de fragilidad para la economía mexicana, en la medida que se ve sujeta a las oscilaciones de la economía internacional y a un alto grado de dependencia de las crisis financieras de los países, o al nerviosismo de los capitales que tienen repercusiones inmediatas en los ámbitos locales.

De 1994 al 2005, el comportamiento de la IED no es equilibrado y muestra oscilaciones que son profundas en algunos años como resultado de la crisis de 1994-1995 y la posterior incertidumbre internacional en torno a la crisis de Asia, Brasil y Rusia que presentaron efectos negativos para México. Repunta significativamente en 1994, con 15 mil 052 millones de dólares, pero cae a menos de $10 \mathrm{mil}$ millones de dólares un año después; se recupera en 1997 y cae nuevamente en 1998 como consecuencia de las crisis internacionales. A partir de 1999 y hasta 2001 mantiene un crecimiento importante, hasta alcanzar su máximo histórico con un valor de 27 mil 429 millones de dólares, para volver a caer en 2003 (15 mil 348 millones de dólares), sube en 2004 (22 mil 283 millones de dólares) y, finalmente, pierde nuevamente participación en el año 2005 (18 mil 934 millones de dólares) (Gráfico 1). En todo el periodo 1994-2005 presenta un decremento anualizado de $-7.1 \%$.

Junto al factor de inestabilidad participativa que ha mostrado, la IED continúa fuera de los márgenes de regulación estatal en cuanto a su destino regional. La participación de la IED en la industria manufacturera califica a este subsector como el más importante, con una participación del $60 \%$ en el año 2005, en tanto las actividades de maquila como las reinversiones por concepto de utilidades se han convertido en el segmento más dinámico, ya que en este año representaron más del 38\% de la IED. Por sí sola, la industria maquiladora ha generado el dinamismo del sector manufacturero, aumentando su participación de un $8.5 \%$ del total en 1994 a $29.5 \%$ en 1998 , aunque posteriormente manifiesta una reducción sistemática hasta llegar a $14 \%$ en el acumulado al 2005 (Cuadro 1). 
Javier Delgadillo Macías

Gráfico 1. México, inversión extranjera directa (millones de dólares), 1994-2005.

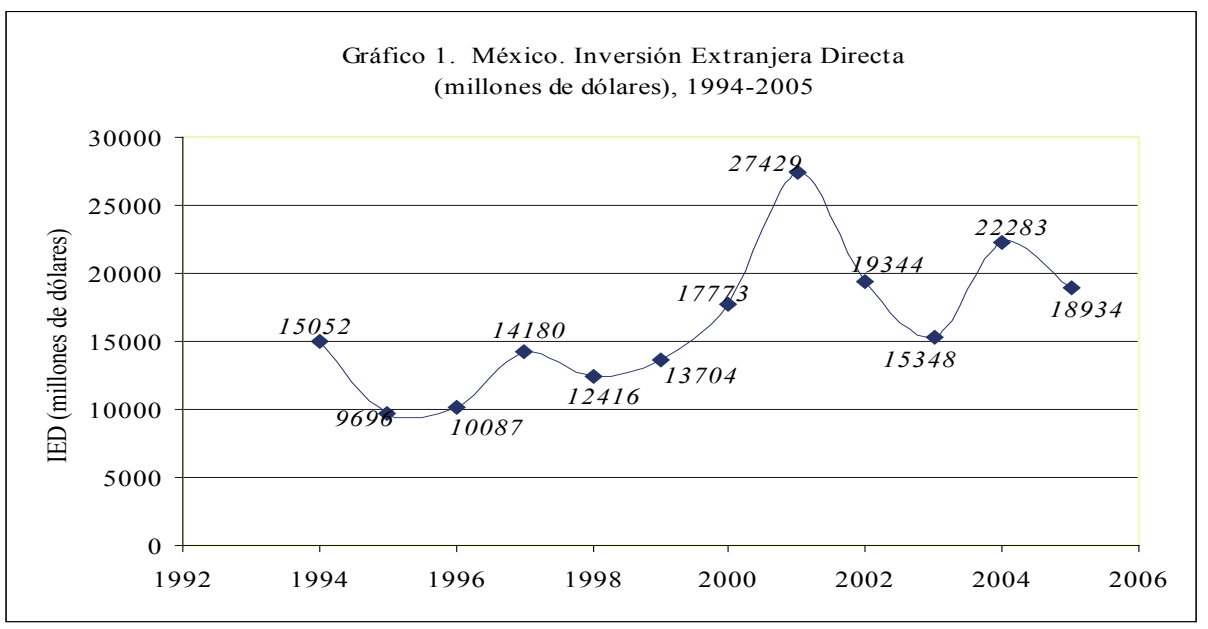

Fuente. Dirección General de Inversión Extranjera, Secretaría de Economía, 2006.

Cuadro 1. México. Inversión Extranjera Directa Realizada por sector económico (millones de dólares), 19942006

\begin{tabular}{|l|c|c|c|c|c|}
\hline \multirow{2}{*}{ SECTORES } & \multirow{2}{*}{$\mathbf{1 9 9 4}$} & \multirow{2}{*}{$\mathbf{2 0 0 0}$} & \multirow{2}{*}{$\mathbf{2 0 0 5}$} & \multicolumn{2}{c|}{ Acum. 1994-2006 } \\
\cline { 5 - 6 } & & & & Valor & Part. \% \\
\hline TOTAL & $10,646.6$ & $17,772.6$ & $18,933.8$ & $193,065.7$ & 100.0 \\
\hline Agropecuario & 10.8 & 91.6 & 2.9 & 456.5 & 0.2 \\
\hline Extractivo & 97.8 & 198.9 & 24.2 & $1,365.6$ & 0.7 \\
\hline Industria Manufacturera & $6,191.9$ & $9,911.9$ & $11,362.7$ & $99,510.4$ & 51.5 \\
\hline Electricidad y agua & 15.2 & 134.0 & 191.9 & $1,683.4$ & 0.9 \\
\hline Construcción & 259.6 & 172.1 & 277.4 & $2,188.1$ & 1.1 \\
\hline Comercio & $1,251.5$ & $2,437.0$ & $2,647.5$ & $19,201.5$ & 9.9 \\
\hline Transp. y Comunicaciones & 719.3 & $-2,081.6$ & $1,172.6$ & $9,402.1$ & 4.9 \\
\hline Servicios Financieros & 941.7 & $4,857.4$ & 943.7 & $41,582.3$ & 21.5 \\
\hline Otros Servicios & $1,158.8$ & $2,051.3$ & $2,310.9$ & $17,675.8$ & 9.2 \\
\hline
\end{tabular}

Fuente. Secretaría de Economía. Dirección General de Inversión Extranjera, 2006.

Entre las principales ramas de mayor participación de la IED, seis se relacionan con el sector manufacturero y cuatro con servicios; el sector automotriz resulta el de mayor participación. La IED se ubica en un número relativamente pequeño de ramas; diez de ellas concentraron durante el periodo 1994-2005 el 53\%.

Por entidad federativa, se observa que la IED continúa la misma tendencia de concentración en los estados más ricos, mas que un relativo redireccionamiento hacia otras entidades. En el caso del Distrito Federal, si bien disminuye de 7 mil
603 millones de dólares en 1994 a 4 mil millones de dólares en 1998, crece significativamente hasta 19 mil 800 millones en el año 2005 producto del ciclo expansivo del TLCAN ${ }^{4}$. A nivel de las entidades federativas ganadoras, Nuevo León, Chihuahua, Baja California y el Estado de México

Habrá de observarse, sin embargo, que en términos relativos la participación del Distrito Federal ha ido decreciendo, pasando del $78.6 \%$ de la IED total realizada en 1994, al 66.4\% para el periodo 1994-1998, cayendo al 57.5\% en el periodo 1994-2005 (tasas de crecimiento anualizadas y acumuladas). Esta pérdida relativa es ganada por las otras entidades con mayor IED registrada. 
Gráfico 2. México, valor agregado de la IED 1994-2005 (variación porcentual anual).

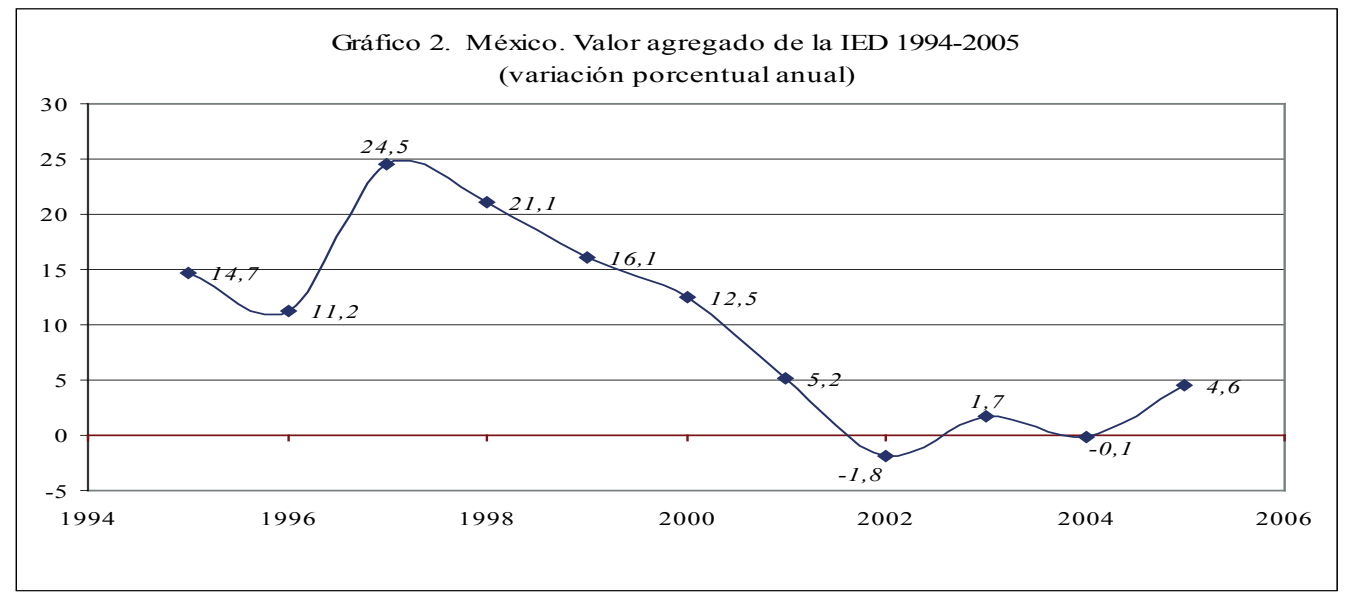

Fuente. Cuadro 1.

se benefician de este proceso desde 1994 a través de la presencia de empresas maquiladoras, pero además se ha incorporado Jalisco dentro de una estrategia similar.

La mayoría de los estudios revisados sobre inversión sectorizada, pero que se abocan a ubicar sus principales impactos territoriales, concluyen que éstas se dirigen a entidades que ofrecen la mayor rentabilidad y son ejecutadas a través de empresas con recursos suficientes para competir. Bajo tal supuesto, tenderán a localizarse y relocalizarse, según las condiciones de ajuste dadas por la creciente integración al mercado internacional. Esta cuestión puede ser oscilante en términos ascendentes o descendentes, pero mantiene una inercia positiva en cuanto a preferencia por los espacios de inversión regional ya prefigurados desde el ciclo de economía protegida. Por ejemplo, el Distrito Federal ha continuado como el principal destino de la IED, le siguen los estados del Norte y Noreste, gracias a su mejor ubicación geográfica con respecto a los Estados Unidos, y las regiones del Noroeste y del Centro Occidente (debido a la presencia de Sonora, Sinaloa y Jalisco). En el año 2000 más de una cuarta parte de las empresas maquiladoras se localizaban ya en el interior del país, con una fuerte presencia en Yucatán, Guanajuato, mientras el Distrito Federal perdió participación, lo cual permite inferir un cambio en los patrones regionales de producción y empleo a partir del
TLCAN. Para el 2005 la participación de la industria maquiladora de exportación mantiene su presencia tanto en el interior del país como en las tradicionales ciudades fronterizas.

Otro indicador representativo del impacto social que ha tenido el TLCAN lo representa la migración de la población mexicana a ciudades de Estados Unidos. Si bien en el momento actual este fenómeno está centrado en la disputa por una nueva regulación de la movilidad poblacional, ahora indocumentada, y es sin duda un proceso acumulativo y derivado de diversas circunstancias históricas de la población mexicana, cabe resaltar su agudización a lo largo de los últimos 20 años. Las promesas que ofrecían al inicio del TLCAN un crecimiento de la economía, la productividad y el empleo en México que, de acuerdo con la hipótesis de convergencia, superarían a los de los dos socios comerciales y, así, frenarían el flujo migratorio sur-norte, simplemente no han hecho acto de aparición en los más de diez años de operación de ese instrumento, de forma tal que el movimiento migratorio se ha incrementado exponencialmente; el producto mexicano ha crecido muy poco, sin que su distribución adquiera mayor progresividad, y la recurrencia del ciclo económico, de cuño nacional o importado, es totalmente visible, arrojando el triple efecto del desempleo, el subempleo y el empleo precario (Novelo, 2006). 
Gráfico 3. Mexicanos radicados en Estados Unidos, 1960-2005

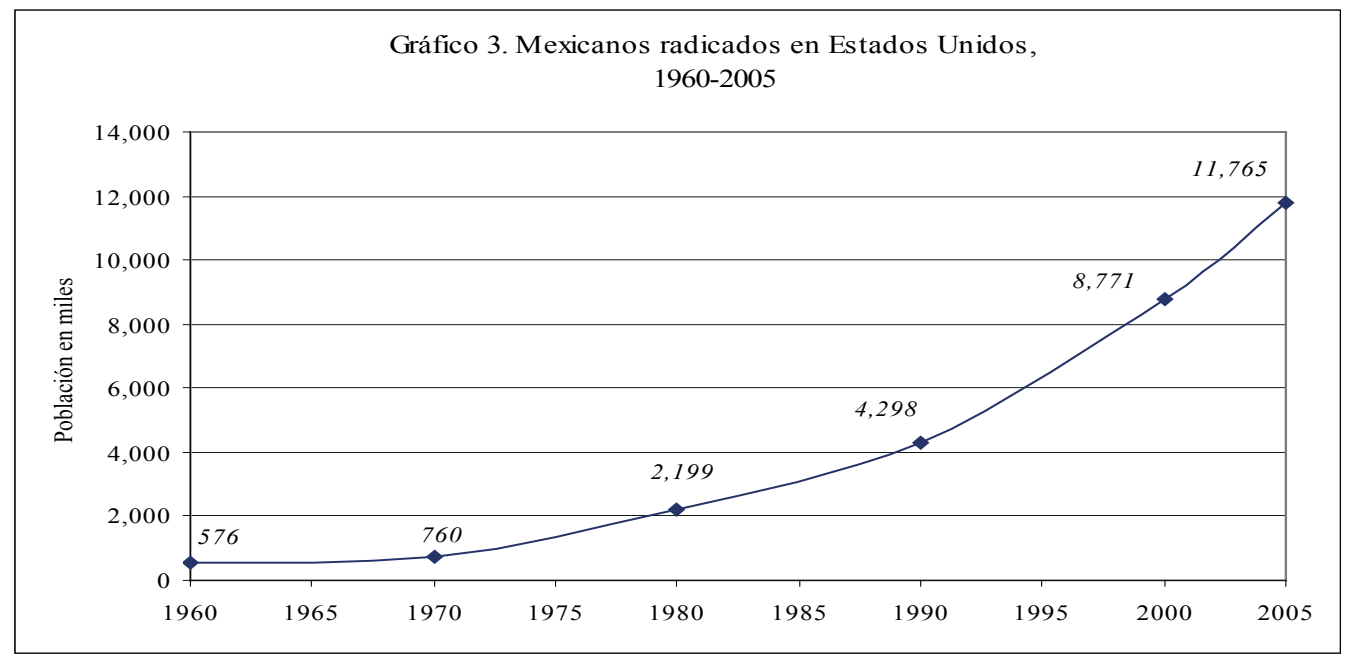

Fuente. U. S: Bureau of Census.

El antecedente de los acuerdos migratorios data del llamado programa bracero instaurado por acuerdo binacional entre Estados Unidos y México después de la segunda guerra mundial y suprimido en 1964. La consecuencia de esta desregulación ha sido la historia acumulada de la "indocumentación" de los migrantes. Francisco Alba (2002) señala al respecto que, después del término de este programa bracero, “...el número de detenciones de ciudadanos mexicanos a lo largo de la frontera entre México y los Estados Unidos comenzó a aumentar, alcanzando un máximo de un millón setecientos mil al año a mediados de los años 80. Luego de un periodo de relativa calma, coincidente con los programas de legalización estadounidenses de fines de esa misma década, el total de detenciones volvió a subir, situándose entre un millón y un millón setecientas mil personas por año hasta el 2000. El número de mexicanos que cambiaron su residencia de México a los Estados Unidos (con o sin autorización) ha registrado también un aumento constante desde la década de los 60, correspondiendo el incremento más pronunciado a las dos últimas décadas, cuando pasó de unos 200 mil al año en los años 80 a 300 mil en los 90.”

Ya en el 2005 el número de migrantes mexicanos que residen en los Estados Unidos asciende a casi 12 millones (gráfico 3), que sumados a los descendientes de segunda y tercera generación alcanzan una cifra de 31 millones de personas, con fuertes lazos sociales, económicos y culturales con prácticamente todas las regiones y municipios de México. Este flujo indocumentado está integrado por población en edad laboral y es predominantemente masculino, situación que se ha acentuado en el periodo del TLCAN, alcanzando flujos promedio anuales de casi 400 mil migrantes temporales mexicanos. Entre el año 2000 y 2005 el 78 por ciento no disponía de autorización para cruzar la frontera, lo que contrasta con la cifra registrada en el periodo 1993-1997, que fue cercana a 48 por ciento.

El otro tema que deriva del fenómeno migratorio tiene que ver con las remesas que los migrantes envían al interior de la república, representando hoy recursos monetarios de cuantía equivalente a las aportaciones que realizan el sector turístico o el energético. El modelo económico actual soporta parte de sus previsiones de mediano plazo en la sostenibilidad de estas remesas, lo cual agrega un elemento más de incertidumbre a la economía mexicana, frente a las decisiones que en el país vecino se vayan decantando.

Por lo pronto, el endurecimiento de la política migratoria ha llevado entre otras medidas 
Cuadro 2. Dinero enviado por migrantes mexicanos desde Estados Unidos, 1990-2005.

\begin{tabular}{|c|c|c|c|}
\hline AÑO & $\begin{array}{c}\text { REMESAS } \\
\text { FAMILIARES } \\
\text { (millones de dólares) }\end{array}$ & AÑO & $\begin{array}{c}\text { REMESAS } \\
\text { FAMILIARES } \\
\text { (millones de dólares) }\end{array}$ \\
\hline 1990 & 2,494 & 1998 & 5,627 \\
\hline 1991 & 2,660 & 1999 & 5,910 \\
\hline 1992 & 3,070 & 2000 & 6,572 \\
\hline 1993 & 3,333 & 2001 & 8,895 \\
\hline 1994 & 3,474 & 2002 & 9,814 \\
\hline 1995 & 3,673 & 2003 & 13,396 \\
\hline 1996 & 4,224 & 2004 & 16,613 \\
\hline 1997 & 4,865 & 2005 & 20,035 \\
\hline
\end{tabular}

Fuente. Banco de México e INEGI, 2006.

a la aprobación de la construcción de un muro antimigrante a lo largo de porciones extensas de la línea fronteriza, y la tendencia republicana que ha gobernado a ese país se caracterizó por el endurecimiento de las medidas antimigratorias, hasta el punto de que en los últimos seis años se incrementó en 135 por ciento el número de agentes fronterizos, se desplegaron seis mil elementos de la Guardia Nacional, se fortaleció el uso de la tecnología para conformar un muro virtual, y se aprobó la construcción de varios tramos de barda con una extensión total de 1,126 kilómetros. Estas medidas, soportadas e impulsadas por una política de contención y rechazo a los migrantes, además de haber probado ya su ineficacia, han causado la muerte de más de 3,500 migrantes mexicanos.

En los últimos 25 años el dinero enviado por la población migrante ha representado para muchas regiones mexicanas un factor de sobrevivencia e incluso de dinamismo económico de varios municipios del centro del país; su incremento en el periodo ha sido sorprendente, pasando de 2 mil 494 millones de dólares en 1990, a más de 20 mil millones de dólares en el 2005 (Cuadro 2 y Mapa 1).

Sin embargo, no se puede apostar a esta fuente monetaria mayores impactos favorables a los hasta ahora alcanzados, sobre todo porque la curva de incremento que aún se mantiene, al parecer y de acuerdo con especialistas, tenderá a reducirse en los próximos años.
Los impactos territoriales y la sociología de las remesas llevan a apuntar algunas hipótesis como las que señalan Cortina et al. (2005):

Es probable que el flujo de remesas a México decrezca durante la década. Fenómenos como la reunificación familiar, la posible aprobación de iniciativas en el Congreso estadounidense a favor de los derechos laborales y políticos de los inmigrantes en Estados Unidos, y cambios en el número y/o las características de los emigrantes, reducirán en primera instancia la tasa de crecimiento de las remesas y, finalmente, su monto general.

Solo una pequeña proporción de las remesas se envía a instituciones para proyectos de inversión en la comunidad o microfinanciamiento particular. En su gran mayoría, los remitentes envían el dinero directamente a sus familias, en especial para consumo primario.

La distribución de las remesas no es uniforme en el territorio nacional: los estados con menor ingreso per cápita no son los que necesariamente reciben más. Diez estados de la República reciben $70 \%$ del monto total de las remesas, mientras que el restante $30 \%$ se distribuye en 23 estados De hecho, cinco de los 10 estados con los niveles más bajos de ingreso per cápita, educación y salud de México son receptores minoritarios de remesas. 
Mapa 1. Distribución geográfica de las remesas enviadas de Estados Unidos a México, 2005

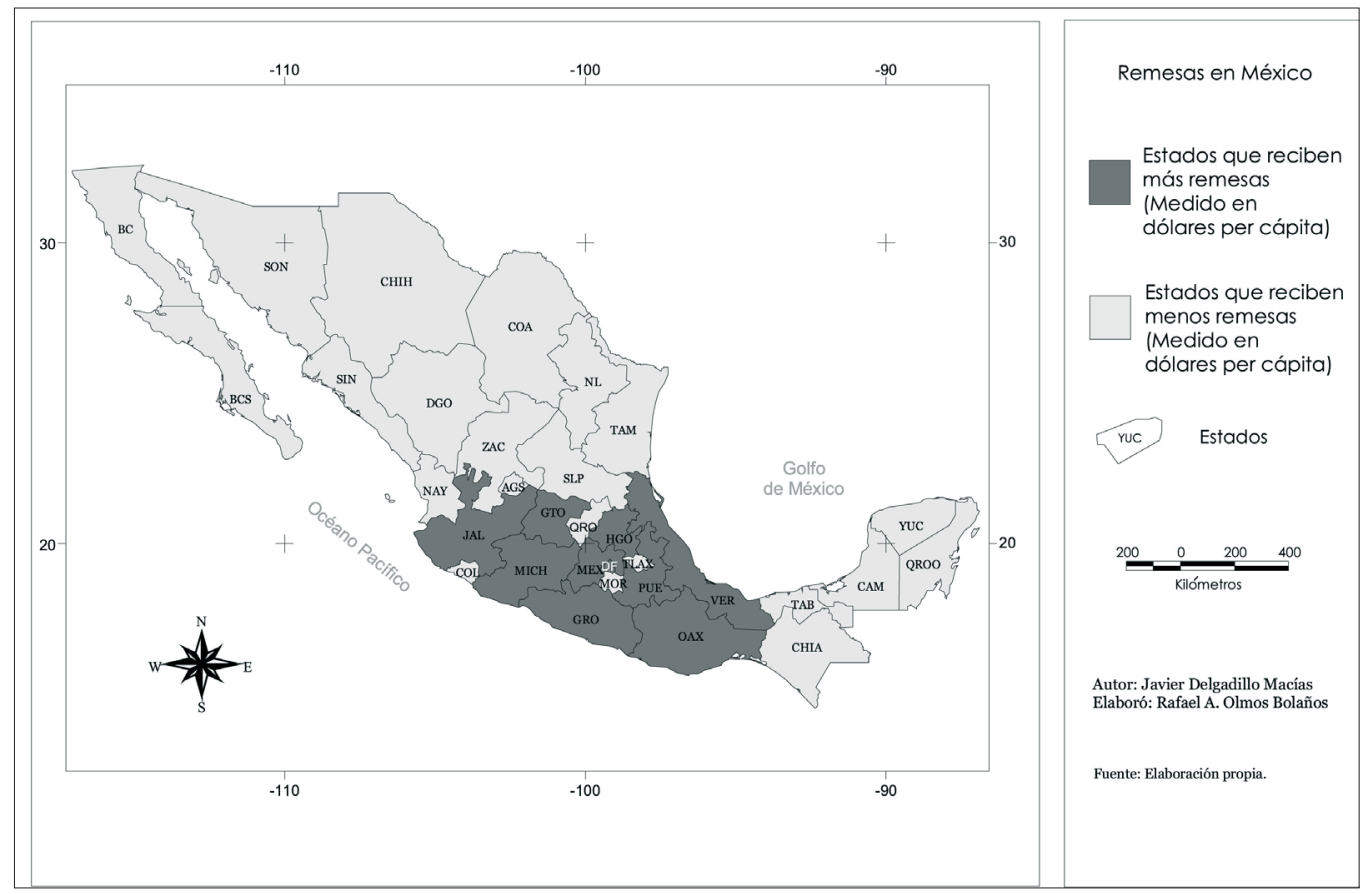

Fuente. Elaboración propia a partir de información de Banco de México 2006 y Consejo Nacional de Población (CONAPO) 2006.

El ranking de las remesas por entidad federativa en 2005 se ubicó de la siguiente manera: Michoacán con dos mil 594.7 millones de dólares; Guanajuato con mil 714.5 millones de dólares; Jalisco con mil 693.1 millones de dólares; Estado de México con mil 675.2 millones de dólares; Distrito Federal con mil 452.1 millones de dólares; Puebla con mil 173.9 millones de dólares; Veracruz con mil 154.7 millones de dólares; Oaxaca con mil 002.2 millones de dólares; Guerrero con 957.4 millones de dólares; Hidalgo con 718.4 millones de dólares.

\section{Efecto dispersor del TLCAN}

La concentración de la actividad económica en el centro del país durante la vigencia del modelo de economía protegida con la apertura económica los patrones de localización ha modificado. En ello también influyó la caída del mercado interno a causa de la crisis de la economía, el impulso al cambio estructural a partir de una mayor competencia, el repliegue del estado en la economía, la desregulación de varios sectores, así como el incre- mento de las inversiones externas y la reacción de grupos nacionales de empresarios que invirtieron para competir en el exterior. Todos estos factores disminuyeron el efecto que antes tenía la cercanía con los mercados locales nacionales como criterio de localización de las empresas y llevaron a una reorganización de los procesos en condiciones de competitividad internacional; sin embargo, esto no cambió las distorsiones regionales y la permanencia de la brecha entre regiones más desarrolladas y menos desarrolladas.

Un estudio realizado con información del periodo comprendido entre 1980 y 1999 concluye que en cuanto a concentración de la actividad económica el Distrito Federal registró la más alta en todos estos años, si bien no se mantuvo constante. Le siguieron el Estado de México, Nuevo León y Jalisco. Estas últimas entidades incluso incrementaron su participación según el criterio de venta de las empresas más grandes. A partir de 1986 y hasta 1990 aumentaron su participación Coahuila, Chihuahua, Sonora, Tamaulipas, y Baja California; en el centro lo hicieron Guanajuato, 
San Luis Potosí y Tlaxcala, pero lo pierden Querétaro y Puebla; Veracruz y Sinaloa se mantienen sin variación. Ese comportamiento se presenta de igual manera entre 1991 y 1999 y se identifica con un patrón de desconcentración que coincide con la más baja participación del Distrito Federal. Sin embargo, en 1994 el Distrito Federal aumentó su participación junto con Nuevo León y Jalisco en detrimento del Estado de México; la participación de Nuevo León comenzó a ser mejor que la del Estado de México y la de Jalisco estaba muy cerca de alcanzarlo (Corona, 2003).

Un efecto adicional está relacionado con el patrón de distribución espacial de las actividades económicas. Considerando a las empresas más grandes de México, éste presentó una desconcentración a partir de 1980 como consecuencia de la apertura de la economía y del menor dinamismo del mercado interno. Con la globalización se ha formado un conjunto de nodos, en especial de ciudades que responden a las exigencias del proceso de acumulación a escala mundial. Pero esto no supone eliminar el problema de las desigualdades regionales, aunque se observa una relativa reconfiguración del territorio, dada por una presencia más dispersa de las empresas en función de las ventajas que han ofrecido algunos gobiernos estatales que, ante la falta de claridad de destino de las políticas económicas nacionales y su direccionamiento regional, fincan sus expectativas de mejoramiento económico en las oportunidades de inversión y desarrollo que podría ofrecer el TLCAN y otros países fuera de esta área de influencia (Corona, 2003).

Otro estudio que considera el comportamiento registrado por el PIB per cápita en el periodo 19931999 (Messmacher, 2000) igualmente muestra un aumento en la desigualdad regional absoluta a partir de 1993, aunque la dispersión relativa no aumentó. Según este análisis, los cambios estructurales en la economía parecen haber tenido dos efectos: a) en el sectorial, la tasa de crecimiento del sector manufacturero se ha incrementado sustancialmente a partir de 1993 y se expandió más que cualquier otro sector a excepción del transporte, almacenaje y comunicaciones. Por este efecto crecieron a mayores tasas los estados donde la manufactura representa una elevada proporción de la producción; b) en lo regional, los estados del norte han tenido un desempeño mejor que el esperado, dada la estructura de su producción. Lo anterior solo expresa las tendencias históricas del desequilibrio, junto con las limitaciones estructurales para frenarlo.

La conclusión en ambos estudios es coincidente en resaltar la pervivencia de la desigualdad e incremento de las históricas asimetrías regionales.

Por nuestra parte, los datos analizados muestran que para el año 2006 el PIB per cápita del Distrito Federal es seis veces superior al de los estados más pobres (p. ej. Oaxaca o Chiapas) y dos veces más que el promedio nacional (gráfico $4)^{5}$. Los estados más pobres se ubican en la región Sur y Este.

Aunque no hay evidencias contundentes de que las reformas de la economía realizadas por el Estado mexicano, junto con el TLCAN, hayan llevado a una dispersión sustantivamente mayor que la observada en los últimos 30 años, el hecho es que no se han reducido las diferencias regionales, según los indicadores positivos o de impacto que se utilicen como parámetro. El análisis de la evolución de las determinantes de largo plazo sugiere la posibilidad de un incremento de la desigualdad contrario a lo que las reformas estructurales perciben. Los Estados del norte presentan mejor desempeño, constituyendo una evidencia de los efectos regionales diferenciados, aunque esto no constituye una novedad, ni antes ni después de la aplicación del TLCAN (Messmacher, 2000).

El criterio de la inversión como factor de desarrollo y competitividad de la economía mexicana en el contexto del TLCAN parte del supuesto de que las economías que basan su crecimiento en la inversión tienen más oportunidades de desarrollo en el largo plazo. Al producir excedentes existe la posibilidad de generar ahorro interno y externo, pero también supone inversiones en la innovación, en la medida en que no existe país que haya logrado un alto desarrollo económico y

Nota: Para el año 2006, la información sobre el PIB per cápita por entidad federativa se obtuvo a partir de cálculos proyectados sobre la base del último año disponible (2004) en el Sistema de Cuentas Nacionales de México. 
Javier Delgadillo Macías

Gráfico 4. PIB Pér Capita por entidad federativa, 2006

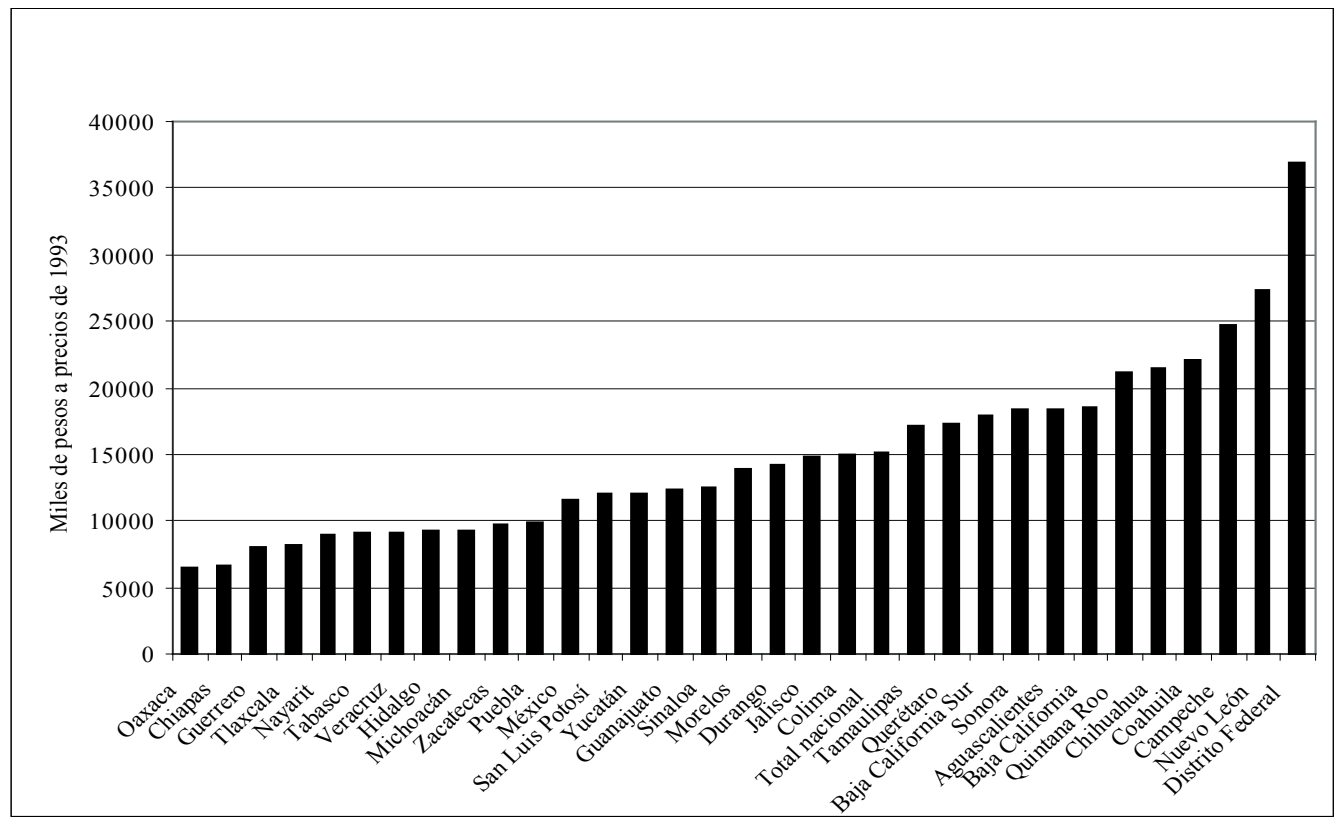

Fuente. Elaboración propia.

social sin una estrategia basada en inversión previa en innovación y desarrollo tecnológico y son, sin duda, estos factores los determinantes en la competitividad en un mercado abierto. En el mismo sentido, el Plan Nacional de Desarrollo 2001-2006 planteaba lograr el crecimiento con calidad con base en tres objetivos: a) promover una inserción ventajosa del país en el entorno internacional; b) promover mayores flujos de inversión extranjera directa; y c) fortalecer el mercado interno; sin embargo, estos objetivos se vieron incumplidos, debido principalmente a una situación de alta competencia regional y mundial que se mueve más allá de la simple aplicación de un esquema sustitutivo o de privilegio a la inversión extranjera especulativa (Ruiz, 2002).

Aquí es importante cuestionar cómo satisfacer los requerimientos de la competencia externa que favorezca revertir la fase de región rezagada en el escenario mundial, impulsando a la vez una conciliación mínima de los indicadores de crecimiento intrarregionales para aprovechar de mejor manera las ventajas internas y evitar los costos futuros de un mayor desequilibrio, sobre todo si reconocemos que la débil competencia en México es resultado del poder excesivo de ciertos actores y de un arreglo institucional diseñado para otro entorno político y económico. Esto tiene efectos negativos en materia de productividad y crecimiento (Elizondo, 2006).

Una primera aproximación es el conocimiento de los factores de distribución y su comportamiento y efectos más recientes. $\mathrm{Al}$ respecto, el Banco Mundial establece en sus balances sobre el desempeño de México aspectos relativos a las disparidades que se mantienen aún con la liberalización económica (en particular véase: Lessons from NAFTA for Latin America and the Caribbean countries: a summary of research findings, 2003): "El TLCAN ha tenido efectos positivos en México pero éstos podrían haber sido mejores... si bien ofrece nuevas oportunidades económicas, las lecciones para otros países que negocian con Estados Unidos apuntan a que el libre comercio por sí solo no es suficiente sin una reforma significativa de las políticas e instituciones. El TLCAN no basta. Las esperanzas de que México daría pasos agigantados para alcanzar a Estados Unidos se vieron reducidas 
Gráfico 5. PIB general por entidad federativa, 2006. Participación porcentual.

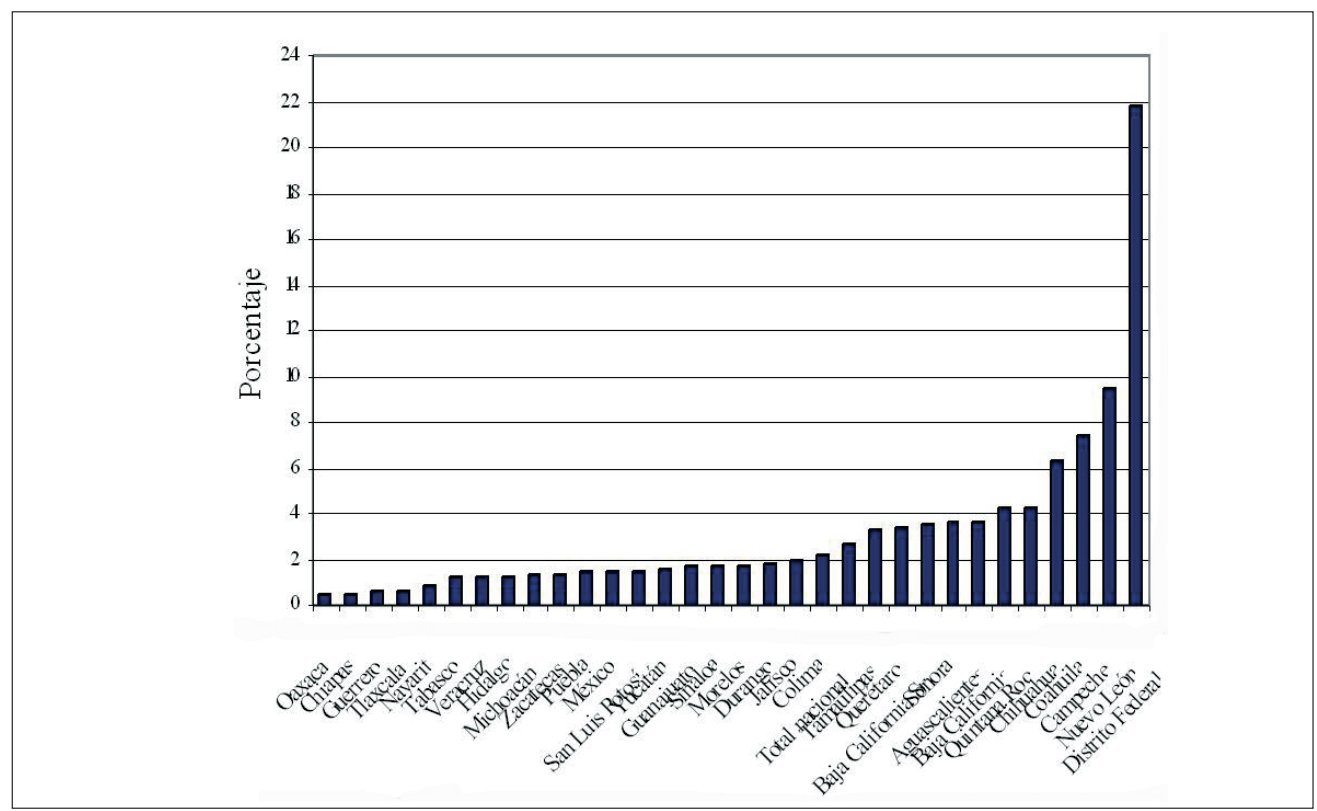

Fuente. Elaboración propia.

por la insuficiente inversión en educación, innovación e infraestructura, así como la baja calidad institucional, un término que abarca la rendición de cuentas, la eficacia regulatoria, el control de la corrupción y temas afines. Más aún, los beneficios del TLCAN y del comercio en general han sido desiguales entre las regiones y sectores.

El tratado definitivamente conectó aún más a México con la economía más dinámica del mundo, pero el desarrollo del país en el transcurso de la década de los noventa, incluyendo el periodo del TLCAN, fue disparejo. Las regiones y los sectores más desarrollados y competitivos se han beneficiado de la liberalización comercial, mientras que aquellos rezagados no lo han hecho. El desafío sigue siendo ampliar los beneficios a toda la sociedad.

Algunos de los efectos desiguales son los siguientes: El aumento de los salarios de los trabajadores con niveles más altos de educación en relación con aquellos con niveles más bajos, que comenzó con la liberalización unilateral de la década de los ochenta, en gran parte se mantuvo con el TLCAN. Los estados del norte y del centro crecieron con más rapidez en los años noventa, reduciendo modestamente la brecha de ingresos con los del Distrito Federal, pero los estados más pobres del sur crecieron menos debido a los bajos niveles de educación, infraestructura y calidad de las instituciones locales. Las grandes firmas mexicanas aumentaron su acceso a los mercados de capital del norte ante la restricción del financiamiento interno tras la crisis del tequila, mientras que el crédito se mantuvo restringido para las pequeñas y medianas empresas. En el campo aumentó ligeramente la productividad de las tierras irrigadas, pero no se benefició la agricultura no exportadora, sin sistema de regadío" (Banco Mundial, 2003).

\section{Reconfiguración territorial y asimetrías regionales}

Un análisis de los datos hasta ahora expuestos muestra que hay elementos favorables de desempeño: aumentan las exportaciones manufactureras y petroleras, aumenta la IED, y continúa consolidándose el esquema de regiones favorecidas respecto de otras estancadas, quizá con algunas ligeras variaciones. Como contraparte, también se presenta una fase de ascenso de las contradicciones, desigualdad regional, inequidad social y conflictos sociales. 
En cuanto a los valores de participación general ajustados a precios de 1993, las entidades federativas que aportan mayor proporción al PIB nacional se localizan en el Centro y Occidente del país (Distrito Federal, Estado de México y Jalisco) y en el Norte (Nuevo León, Chihuahua, Baja California y Coahuila), superando cada uno valores del 4\%; el sector que más contribuyó a esta dinámica fue la industria manufacturera, a lo cual se agregó, por la inercia derivada del crecimiento, el de los servicios; otros como el agropecuario y la construcción mantuvieron una contribución poco significativa. Los estados de menor aportación corresponden a una distribución geográfica dispersa por el territorio nacional, destacando entidades ubicadas en las costas y centro del país (Gráficos 5 y 6).

Las tasas de crecimiento del PIB ubicaron al Norte ya con una clara ventaja, consolidando su dinámica ganadora; los comportamientos positivos en algunos estados fuera de esta región no fueron suficientes para revertir esa tendencia, ni para reposicionar a las regiones perdedoras en los indicadores positivos de la apertura.

En la misma dinámica de periodos anteriores al TLCAN, estados del Centro mantienen relativa ventaja, aunque con ligeras variaciones intrarregionales; Aguascalientes, Guanajuato y Querétaro presentan valores equivalentes a los del norte del país, mientras que el Distrito Federal observó una tendencia declinante, al registrar una tasa de crecimiento de apenas $1.46 \%$.

En el Sur destacan dos estados que lograron un repunte con respecto a las condiciones que mantenían anteriormente: Quintana Roo creció a una tasa de $4.49 \%$ y Yucatán al 3.54\%, valores que resultan incluso superiores a algunos de los estados del Norte del país; por un lado se debe a una fuerte presencia de empresas maquiladoras que se desplazaron del centro del país y que incluso han entrado ya a una nueva fase de movilidad, y en el otro al renglón del turismo que no irradia beneficios e incluso puede ser volátil e influir más en distorsiones regionales que en un mejoramiento sustentable a lo largo del tiempo.

Una primera conclusión señala que las entidades del Sur, junto con otros estados del Centro y el Este que históricamente han presentado condiciones de atraso, manifiestan signos de empeoramiento. En esta condición encontramos los casos de Chiapas, Hidalgo, Guerrero, Oaxaca y Veracruz, cuya tasa de crecimiento del PIB se ubicó en valores inferiores al $2 \%$, incluso en algunos años del periodo mostró un comportamiento negativo y en determinados sectores este comportamiento fue permanente (Gráfico 6 y Mapa 2).

A pesar de su declinación relativa en el crecimiento, con aproximadamente el $23 \%$ de participación, el Distrito Federal sigue generando casi la cuarta parte de la riqueza del país, en detrimento de otras entidades que, al no incentivar sus factores de impulso, continúan en el atraso y como expulsoras permanentes de población.

El Distrito Federal junto con los Estados de México, Nuevo León, Jalisco, Veracruz y Puebla, concentraron más del $50 \%$ del PIB nacional. Si sumamos a las regiones centrales, y se excluye de ellas al Distrito Federal, Puebla y el Estado de México, quedan en una condición de debilidad y solo presentarían su atractivo de amplio mercado de consumo; por esta razón y de seguir la tendencia es muy probable que aumenten las distorsiones regionales y un mayor desequilibrio funcional entre una ciudad central poderosa y otros espacios circundantes en condición de mayor atraso. Esta misma situación ocurre en el Norte, con Nuevo León y la zona metropolitana de Monterrey, aunque por el peso especifico que presenta cada estado dentro de la región en su conjunto ayuda a una estructura intrarregional más equilibrada.

El resto de las entidades presenta todavía un nivel de participación poco significativo. Por ejemplo, Aguascalientes, con un fuerte crecimiento en el periodo (5.1\%), apenas si participa con el $0.97 \%$ de la riqueza nacional; Guanajuato con el 3.36\%, Puebla con el 3.23\% y Querétaro con el 1.4\%, o sea, con todo y su dinamismo, no generan ni la mitad de la riqueza que aporta el Distrito Federal. Las demás entidades del Sur, Este y Península de Yucatán, ubicadas en condiciones de atraso, no igualaron juntas el valor generado por el Distrito Federal y el Estado de México.

En los trece años transcurridos del TLCAN, la IED ha sido determinante tanto para afianzar el 
Gráfico 6. México. PIB Regional 1993-2004 (porcentajes).

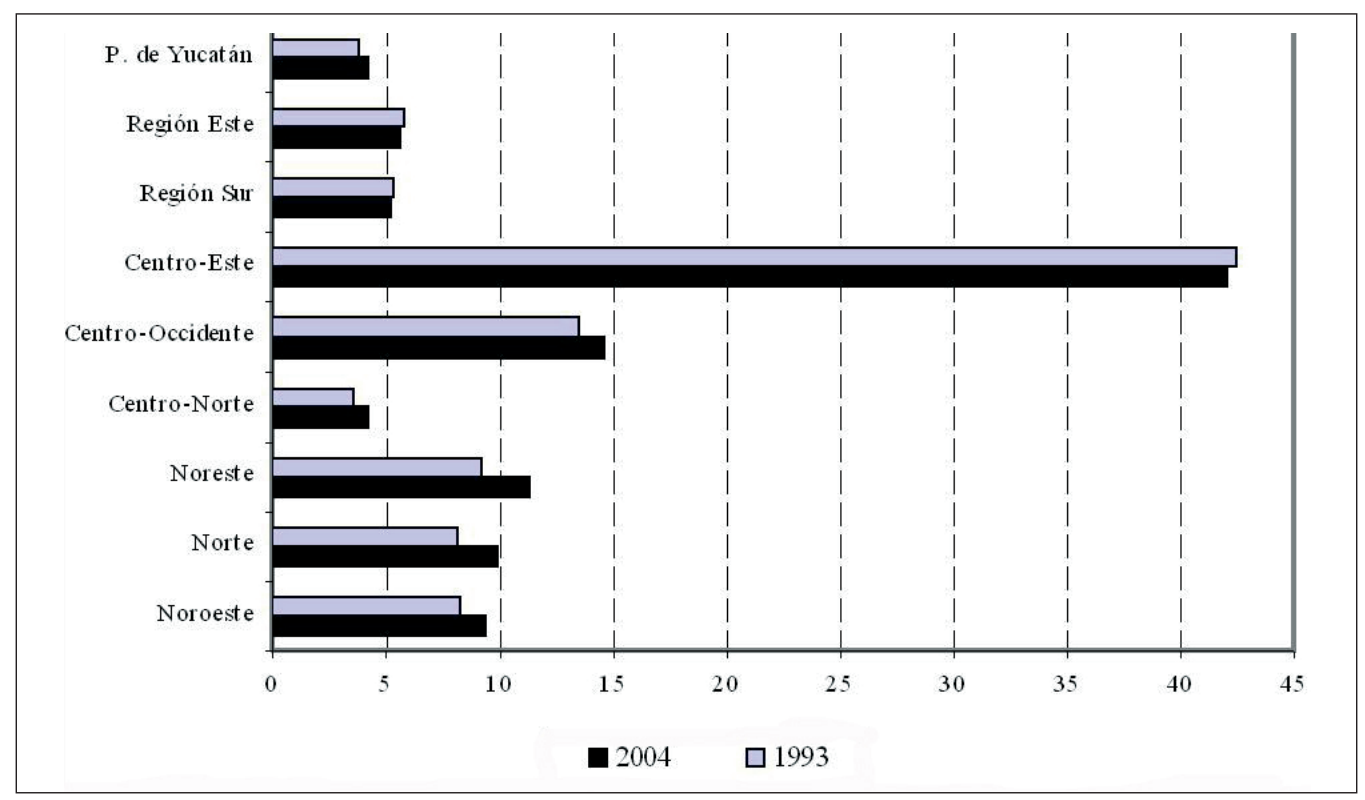

Fuente. Elaboración propia.

avance del proyecto, como para reforzar el rango ganador, perdedor o emergente de las regiones. En este periodo se registró un flujo acumulado superior a 123 mil millones de dólares; sin embargo, su distribución muestra de nuevo las inequidades regionales y determina ahora de manera más clara la tendencia estructural al desequilibrio.

Con todo y que presentó una abrupta declinación en los años posteriores inmediatos a la crisis de 1994, el Distrito Federal continúa como el principal receptor en este rubro; de un poco más de 7 mil 600 millones de dólares que recibió en 1994, en 1995 y 1996 disminuyó a menos de 5 mil millones de dólares, se recupera en 1997, cae de nuevo en 1998 y 1999 y en el 2001 capta una cifra récord de cerca de 19 mil 500 millones de dólares, que correspondió a cerca del $80 \%$ de lo captado a nivel nacional.

También el Distrito Federal mantiene una amplia jerarquía en cuanto al destino de la IED, que si bien canalizada en buena parte a ciertas actividades volátiles, de todas maneras genera una elevada distorsión e inhibe las perspectivas de atracción de otras entidades y regiones del país. Tan solo en 1999, que registra el nivel más bajo, el
Distrito Federal captó el $46.02 \%$ de toda la IED que ingresó al país, en el 2001 repuntó al 76.89\% y en el 2002 bajó al 57\%. Aun así, el Distrito Federal prácticamente no bajó de un nivel de captación inferior al 50\% respecto al total nacional.

El comportamiento del flujo regional de la IED se corresponde con el efecto al desequilibrio que inducen otros indicadores y que parecen agudizarse a partir del TLCAN, en tanto las estrategias de inversión derivadas están dirigidas hacia los servicios para mercados de consumo masivos y concentrados, o bien a sectores de la producción con un elevado componente tecnológico como el automotriz y algunas ramas manufactureras, los cuales ya tienen una localización bien definida con base a ventajas de infraestructura acumulada y afinada a lo largo del tiempo.

En esa condición aparece el Estado de México, que por efecto de sus municipios concentrados en la Zona Metropolitana de la Ciudad de México y aún resintiendo los efectos declinantes del Distrito Federal, de todas maneras participa entre el 3 y el $9 \%$ del total de las captaciones a nivel nacional, registrando $5.8 \%$ de crecimiento en el periodo 1994-2006. En tanto el Distrito Federal, con todo 
Javier Delgadillo Macías

Cuadro 3. México. Inversión Extranjera Directa Realizada por Entidad Federativa, 1994-2005. (Millones de dólares)

\begin{tabular}{|c|c|c|c|c|c|}
\hline \multirow[t]{2}{*}{ ESTADOS } & \multirow[t]{2}{*}{1994} & \multirow[t]{2}{*}{2000} & \multirow[t]{2}{*}{2005} & \multicolumn{2}{|c|}{ Acum. 1994-2005 } \\
\hline & & & & Valor & Part. \% \\
\hline T O T A L & $10,646.60$ & $17,772.60$ & $18,933.80$ & $193,065.70$ & 100 \\
\hline Aguascalientes & 28.5 & 81.9 & 68.9 & 828.2 & 0.4 \\
\hline Baja California & 227.1 & 981.6 & $1,008.50$ & $9,916.50$ & 5.1 \\
\hline Baja California Sur & 8.2 & 80.6 & 294.1 & $1,366.90$ & 0.7 \\
\hline Campeche & 2.1 & 11.4 & 10.7 & 149.5 & 0.1 \\
\hline Coahuila & 102.3 & 307.5 & 149.1 & $2,184.00$ & 1.1 \\
\hline Colima & 102.9 & 9.5 & 11.2 & 220.5 & 0.1 \\
\hline Chiapas & 0.4 & 2.2 & 1.4 & 25.2 & 0 \\
\hline Chihuahua & 308.4 & $1,080.70$ & $1,383.30$ & $9,439.30$ & 4.9 \\
\hline Distrito Federal & $7,603.00$ & $8,746.00$ & $8,070.70$ & $111,045.20$ & 57.5 \\
\hline Durango & 21.5 & 38 & -145 & 288.6 & 0.1 \\
\hline Guanajuato & 27.4 & 74.4 & 287.9 & $1,343.30$ & 0.7 \\
\hline Guerrero & 7.1 & 10.7 & 22.7 & 270.1 & 0.1 \\
\hline Hidalgo & 0.1 & -8.4 & -3.7 & 191.3 & 0.1 \\
\hline Jalisco & 64 & $1,195.80$ & 855.8 & $5,697.60$ & 3 \\
\hline Estado de México & 340.5 & 469.8 & 741.5 & $11,173.70$ & 5.8 \\
\hline Michoacán & 8.5 & 29.1 & -5.1 & 303.2 & 0.2 \\
\hline Morelos & 19.4 & 67.4 & -64.4 & 783.9 & 0.4 \\
\hline Nayarit & 5.6 & 44.8 & 104.2 & 478.6 & 0.2 \\
\hline Nuevo León & 937.4 & $2,400.50$ & $4,545.00$ & $20,452.60$ & 10.6 \\
\hline Oaxaca & 0.1 & -1.7 & 4.5 & 15.9 & 0 \\
\hline Puebla & 29.9 & 549.1 & 380.1 & $3,879.40$ & 2 \\
\hline Querétaro & 141.1 & 161.7 & 41.4 & $1,490.70$ & 0.8 \\
\hline Quintana Roo & 38.6 & 97.1 & 121.7 & 926.7 & 0.5 \\
\hline San Luis Potosí & 14.8 & 290 & 116 & $1,161.50$ & 0.6 \\
\hline Sinaloa & 46.2 & 12.2 & 0.9 & 416.3 & 0.2 \\
\hline Sonora & 107.1 & 416.6 & 231.2 & $2,464.40$ & 1.3 \\
\hline Tabasco & 0.6 & 38.9 & 33.5 & 440.7 & 0.2 \\
\hline Tamaulipas & 362.4 & 488.7 & 382.1 & $4,629.70$ & 2.4 \\
\hline Tlaxcala & 19.3 & 4.4 & 46.4 & 247 & 0.1 \\
\hline Veracruz & 10.2 & 24.3 & 238.8 & 661.2 & 0.3 \\
\hline Yucatán & 48.1 & 55.5 & -3.3 & 462.6 & 0.2 \\
\hline Zacatecas & 13.8 & 12.3 & 3.7 & 111.4 & 0.1 \\
\hline
\end{tabular}

Fuente. Secretaría de Economía. Dirección General de Inversión Extranjera, 2006. 
Gráfico 7. México. Distribución de la IED por Entidad Federativa, 1994-2005 (promedio anual acumulado)

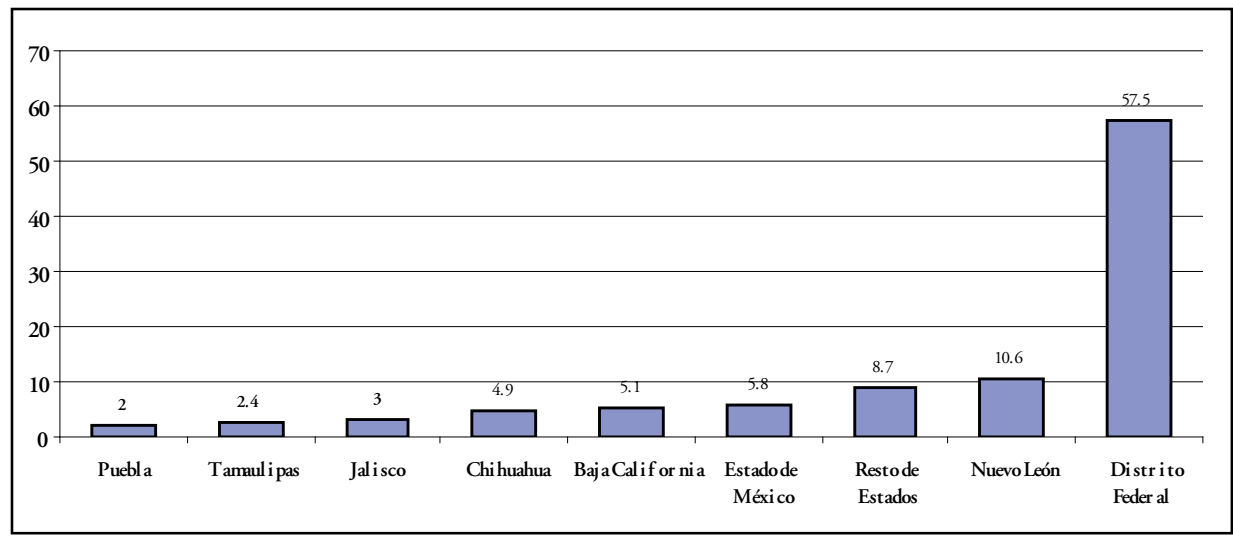

Fuente. Elaboración propia.

Gráfico 8. México. Distribución de la IED por Regiones Económicas, 1994-2005 (acumulado)

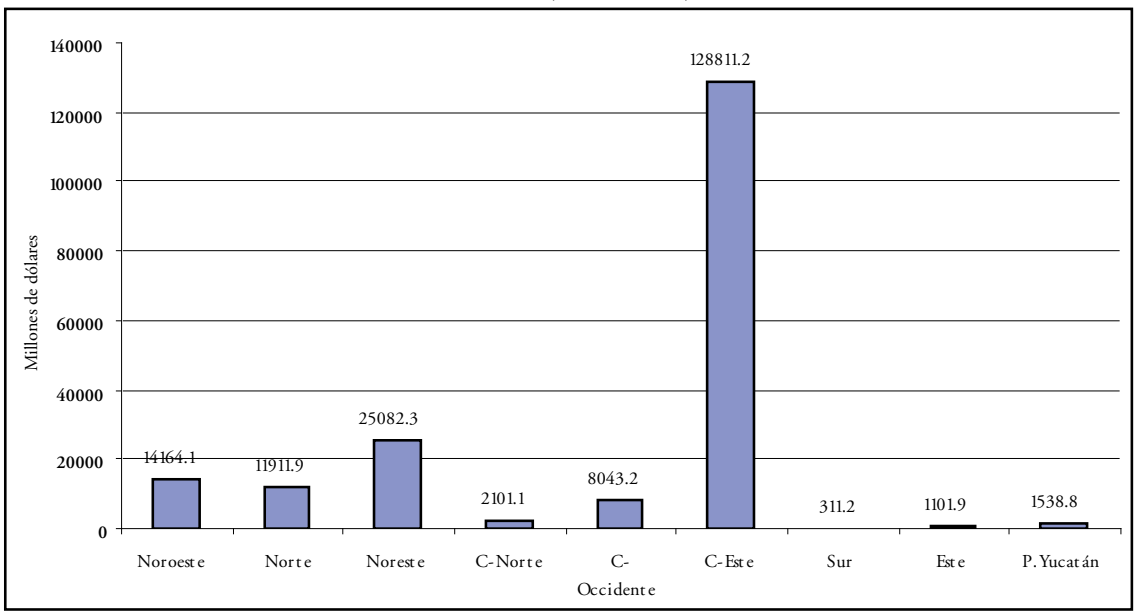

Fuente. Elaboración propia.

y su declinación relativa, mostró una captación del $42.6 \%$ de la IED en 2005. Las regiones del Norte muestra un comportamiento más compacto, ya que los estados que las conforman registran proporciones relevantes de IED: Nuevo León registró en el 2005 el $24 \%$ del total nacional en este rubro, mientras que Chihuahua alcanzó el 7.3\%, Baja California el 5.3\% y Tamaulipas el 2\%.

Otras entidades presentan condiciones ventajosas: Guanajuato, que en 1994 apenas si captó el $0.26 \%$ de la IED total nacional, en el 2005 el $1.5 \%$; en la misma condición encontramos a
Jalisco, que de un $0.6 \%$ captado en 1994 , alcanzó el $4.5 \%$ en el 2005, una participación altamente significativa en la dinámica del TLCAN. Para el resto de las entidades, la captación de IED resultó, además de comparativamente baja, muy errática.

El análisis de las tasas de crecimiento nos permite augurar que de no tomarse otras medidas de atracción y de mejoramiento de infraestructura, es difícil que pueda resolverse el problema del crecimiento y de los desequilibrios territoriales acumulados por esta vía. Excepto Baja California, Chihuahua, Puebla, Sonora, Tabasco, Chiapas, 
Campeche, Jalisco y Nayarit, que registraron tasas positivas en diferentes proporciones, en el resto, incluyendo el Distrito Federal, Estado de México y Nuevo León, el saldo fue más bien negativo. Si bien es cierto que en mucho influyó la recesión de la economía norteamericana y sus efectos de arrastre sobre la economía mexicana, esta situación también es reflejo de la falta de competitividad total que ante el deterioro acumulado presenta ya una buena parte del territorio nacional, en la medida que una buena parte de los capitales se reorientaron hacia otras regiones mundiales como China, el Sureste asiático y algunos países centroamericanos que ofrecen mejores atractivos fiscales y disminución de los costos de producción por la vía de menores salarios.

Un riesgo adicional es el origen mismo de la IED. A pesar que desde 1984 se inicia el proceso de apertura formal de la economía mexicana, y el posterior TLCAN hacía suponer que generaría un proceso de diversificación de nuestras fuentes de financiamiento, en la práctica se han reforzado los lazos de dependencia con Estados Unidos en este rubro. Si bien es cierto que se han firmado múltiples acuerdos comerciales con otros países, el incremento y participación proporcional de Estados Unidos, independientemente de la recesión que tuvo, es notoria. En 1994 el 46.6\% de la IED provenía de ese país, 7.0\% de Canadá, 5.6\% del Reino Unido, $5.9 \%$ del Japón y $2.9 \%$ de Alemania; para el año 2001 este esquema se había modificado radicalmente, ya que Estados Unidos aportó el $77.9 \%$ de la IED, la cifra de mayor concentración a lo largo del periodo TLCAN a favor de ese país, para volver a perder participación en 2005, año en que alcanzó sólo el $51.2 \%$ de la IED.

Parece poco discutible que el TLCAN haya generado un incremento relativo en el volumen de los flujos comerciales, en el volumen monetario de la IED y en el mejoramiento de los niveles de competitividad debido a la presencia de empresas con inversiones sectoriales que requieren tecnología de punta; sin embargo, ello no ha significado una relación favorable en los términos reales de intercambio comercial. El balance del periodo expresa las siguientes conclusiones: la balanza comercial registró un saldo negativo de $-8.7 \%$ (gráfico 9); las regiones ganadoras avanzaron en su proceso de consolidación como tales; las medidas compensatorias vigentes han resultado ineficaces para resolver el problema de los desequilibrios regionales, que se siguen reflejando en el incremento

Gráfico 9. México. Balanza Comercial 1991-2006 (saldo exportaciones/importaciones)

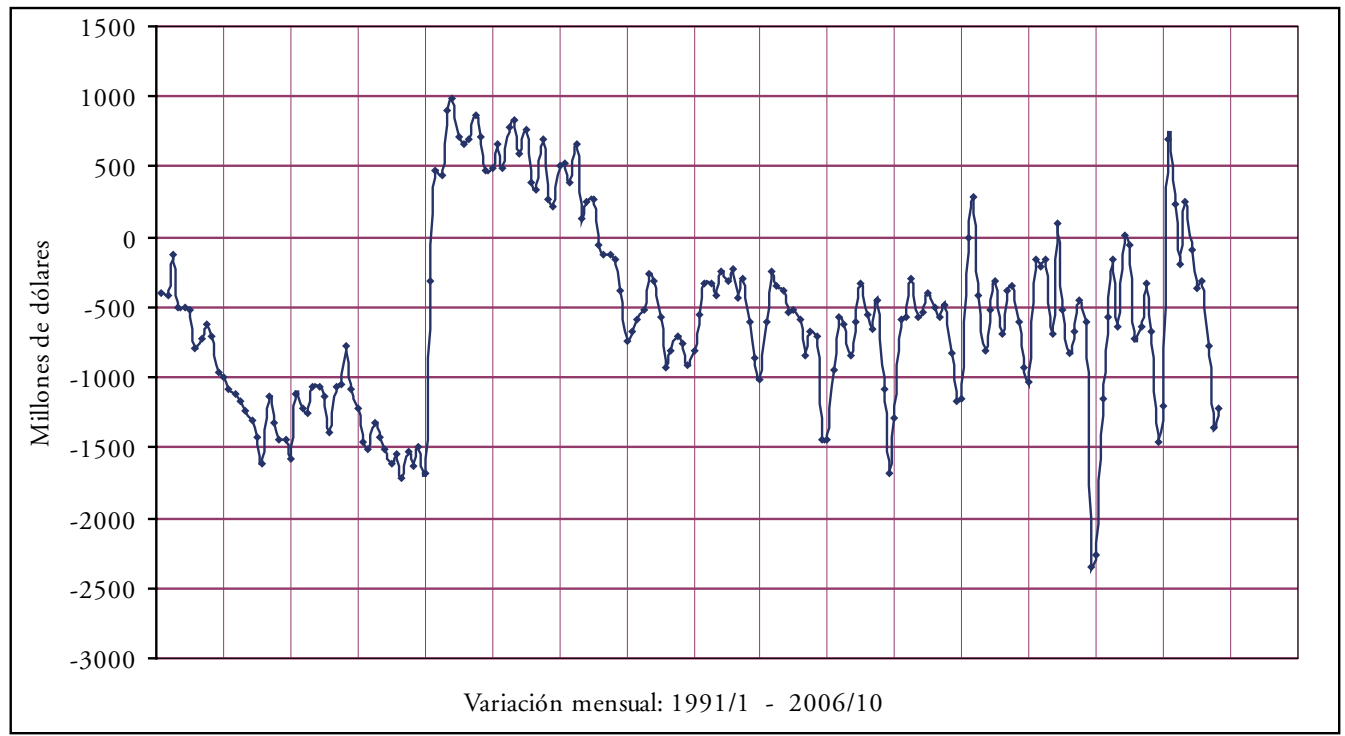

Fuente. Secretaría de Economía con datos del Banco de México. Serie estadística 1991-2006. 
de la pobreza, el deterioro ambiental y la descapitalización permanente tanto de su capital natural como humano sin nuevas opciones internas que lo reviertan, más allá del planteamiento de recuperar las dinámicas anteriores del mercado interno.

Otra conclusión nos lleva a señalar que más que una apertura y diversificación de la economía mexicana por la vía del financiamiento, se trata de una integración a la economía de los Estados Unidos con efectos internos muy desfavorables para la estructura regional de México, en la medida que los mayores flujos de inversión se dirigen mayoritariamente a la Ciudad de México y su zona metropolitana, o a las entidades consolidadas del Norte del país, agudizando la polarización. Esta situación también la reproducen otros países como España, Francia y Suiza, que direccionan inversiones hacia nuestro país, prefiriendo invertir en los centros consolidados.

Por otra parte, hay que destacar también la escasa diversificación que mantiene la estructura económica nacional y la alta dependencia en el intercambio comercial con Estados Unidos. Si bien las exportaciones registraron durante el periodo analizado una tasa de crecimiento del $10.2 \%$ y el de las importaciones de $9.8 \%$, México sigue dependiendo principalmente de las actividades petroleras y de algunas manufactureras sustentadas en empresas maquiladoras de alta volatilidad; tampoco se vislumbran posibilidades de que los Estados Unidos disminuyan los niveles de participación como nuestro principal mercado de origen y destino.

\section{Medición de la desigualdad}

La mayoría de los estudios referenciados a lo largo del texto señalan la evidencia de un periodo de convergencia económica sostenida hasta finales de la década de los años setenta del siglo pasado, y un proceso de divergencia a partir de la instauración del modelo de apertura iniciado en el primer quinquenio de la década de los ochenta (véase también Esquivel, 1999). Para el periodo que comprende el TLC, el análisis que se realizó refuerza estas evidencias y nos permite hablar de entidades federativas que continuaron un proceso favorable y otras que han registrado efectos desfavorables.
El índice de autocorrelación espacial de Moran que se utilizó para confirmar la hipótesis del trabajo, tiene como característica el poder evaluar con significancia estadística si la actividad económica de una entidad federativa está o no correlacionada con la actividad económica de los estados que le son físicamente cercanos. Si no existiera autocorrelación espacial del PIB per cápita a nivel estatal, se esperaría que la distribución del PIB fuera aleatoria. Por el contrario, si existiera autocorrelación espacial del PIB per cápita, se esperarían aglomeraciones de estados con niveles similares en su PIB. En este sentido, el índice de Moran puede verse como una aproximación al grado de "dependencia regional" que puede tener la actividad económica en una región o un conjunto de regiones.

Formalmente el índice de Moran es calculado a través de la siguiente expresión:

$$
I=\frac{n}{s} \frac{\sum_{i=1}^{n} \sum_{j=1}^{n} w_{i j} z_{i} z_{j}}{\sum_{i=1}^{n} z_{i}^{2}}
$$

donde $\mathrm{n}$ es el número de estados del país analizados, wij son los elementos de una matriz binaria de contigüidad, s es la suma de todos los elementos de la matriz W y, zi y zj son valores estandarizados del logaritmo natural del PIB per cápita del estado i y j. El Moran puede interpretarse como una medición estandarizada de la autocovarianza de una variable una vez que se impone una matriz de distancia.

El índice de Moran tiene un valor esperado de no autocorrelación que está dado por la siguiente expresión:

$$
E(I)=\frac{-1}{n-1}
$$

Pruebas de inferencia estadística basadas en supuestos de normalidad o en distribuciones experimentales pueden ser utilizadas para aceptar o rechazar la hipótesis nula de no autocorrelación espacial.

El resultado que se resume en el gráfico 10 muestra la evolución y la distribución del índice 
Gráfico 10. Autocorrelación Espacial del PIB per cápita estatal

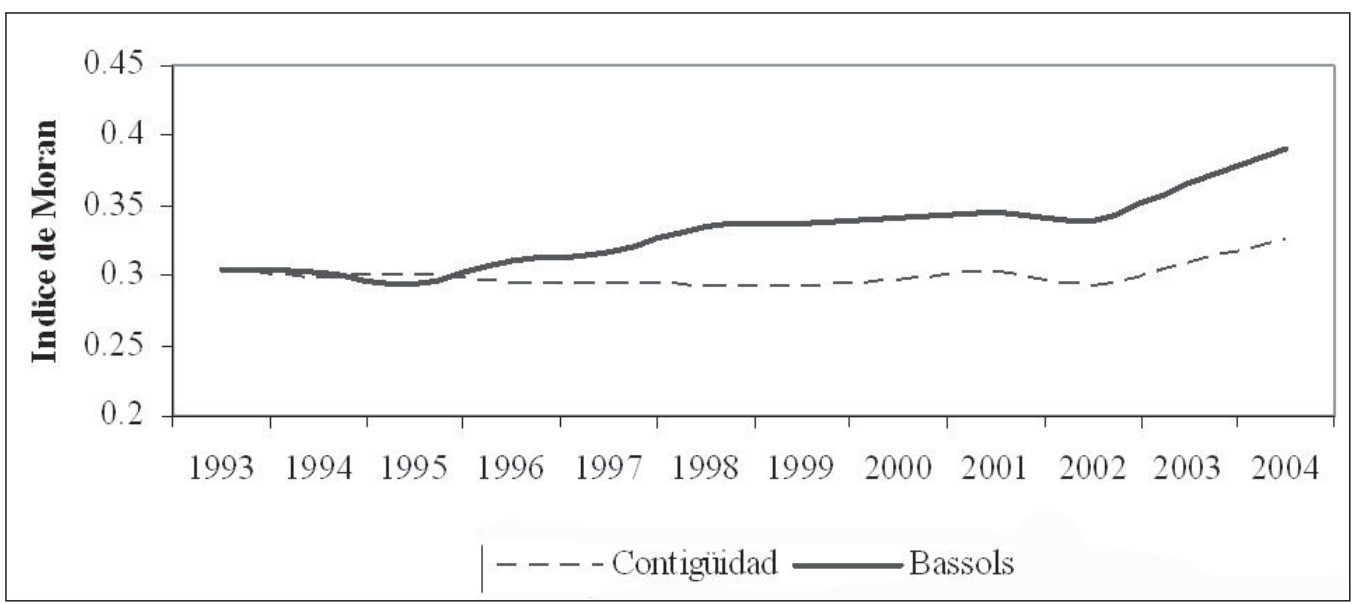

Fuente. Elaboración propia.

de Moran del PIB per capita a nivel estatal. En su construcción se utilizaron dos criterios de interacción espacial entre los estados para medir la autocorrelación espacial del PIB per cápita. El primero es un criterio de contigüidad de primer orden (estados vecinos), y el segundo se basa en la regionalización de Bassols (1999). Los resultados muestran que el PIB per cápita a nivel estatal despliega autocorrelación espacial global estadísticamente significativa y es importante señalar que esta autocorrelación espacial ha venido en ascenso desde el proceso de apertura comercial. Este patrón es consistente con cualquiera de los dos criterios de interacción espacial utilizados; en particular se destaca que el criterio de Bassols acentúa el nivel de autocorrelación espacial.

La matriz de interacción de Bassols involucra, además de la distancia física, otros elementos que están asociados a factores institucionales e histó- ricos que influyen en la formación de una región. De esta manera, este patrón de comportamiento espacial observado que ha tenido el PIB per cápita en la última década fortalece la hipótesis sobre el incremento en la desigualdad territorial que ha traído consigo la implementación del TLCAN. El incremento de la autocorrelación del PIB per cápita a nivel estatal también se ha documentado en otros trabajos (véase Aroca, Bosch y Maloney, 2005).

El paso siguiente consistió en la aplicación de un modelo de convergencia condicional propuesto por Valdivia (2007), desagregado a nivel estatal para el periodo 1994-2005. El modelo considera las principales asociaciones entre pares de variables, que para nuestro caso fueron PIB per cápita por estado/remesas y PIB per cápita por estado/IED. La ecuación de convergencia estudiada es la siguiente

$$
\ln \left(\frac{x_{2004}}{x_{1994}}\right)=\alpha+\beta x_{1994}+R E M / P I B+I E D / P I B_{1994}+C H_{1995}+\varepsilon
$$


Gráfico 11. Crecimiento del PIB per cápita (1993-2004)

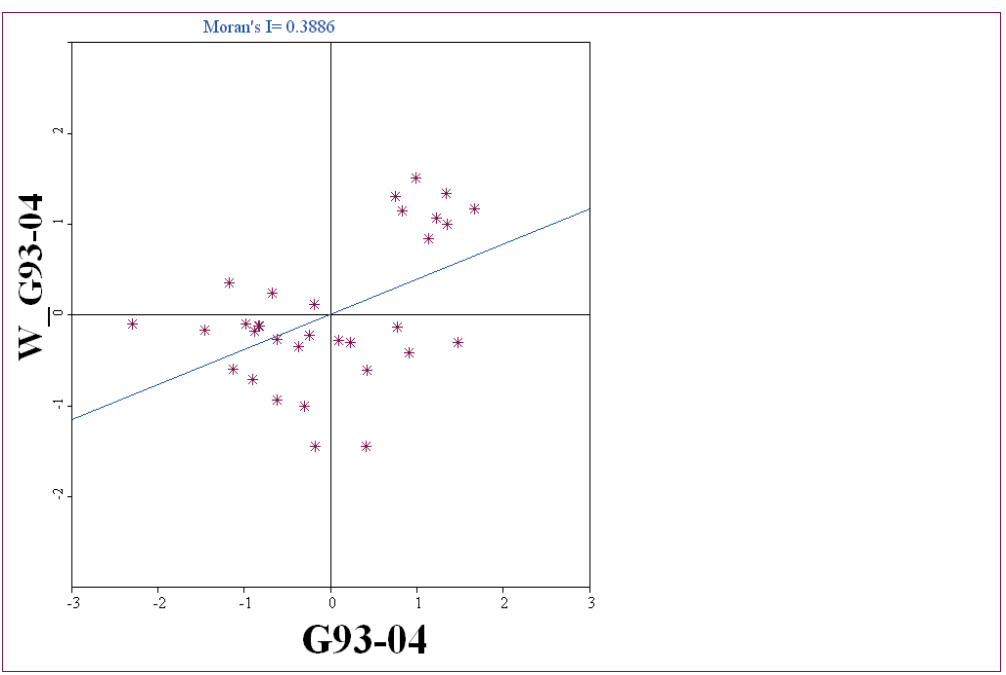

Fuente. Elaboración propia.

Donde $\mathrm{x}$ es un vector del PIB per cápita por estado, REM/PIB es un vector del crecimiento anual promedio de la participación de las remesas respecto al PIB por estado para los años 1995, 2000, 2003 y 2004, IED/PIB1995 es un vector que denota la condicional inicial de la participación de la IED respecto al PIB por estado (año 1994) y CH es un vector proxy del capital humano construido por medio del porcentaje de la población mayor de 5 años que se encontraba estudiando en 1995.

El procedimiento para las estimaciones de la ecuación (2) se realizó por medio de mínimos cuadrados ordinarios omitiendo la variable de remesas. Los resultados indican que cuando la ecuación (2) sólo contiene la condición inicial de la IED (1994) y el capital humano de 1995, se obtiene convergencia condicional en el PIB per capita. Este resultado es consistente ya sea considerando a todos lo estados como también excluyendo a los estados petroleros (Campeche y Tabasco). De los resultados obtenidos se observa que la IED/PIB inicial tiene un efecto positivo y estadísticamente significativo sobre el crecimiento del PIB per capita. Cuando se estima la ecuación completa (2), la evidencia de convergencia ya no es tan contundente pues desaparece para los 32 estados del país pero prevalece para el caso de los
30 estados que excluyen a los petroleros. Si este último caso fuera el más apropiado, entonces no sólo encontraríamos que la IED inicial contribuye al proceso de convergencia sino también la tasa de crecimiento tíe las remesas pero de forma negativa. Este último resultado tiene implicaciones interesantes pues arroja un resultado anticíclico (a nivel regional) del papel de las remesas, es decir, los estados que tienen un desempeño pobre (región central y sur del país) están siendo compensados por los nuevos flujos de remesas. Se finalizó la validación estableciendo una clasificación ajustada a los resultados del análisis de Moran y de convergencia condicional de las entidades federativas y representados en el gráfico 11 .

La gráfica muestra la ubicación de las entidades federativas de acuerdo al PIB per cápita 1993-2004, donde el eje de las Y corresponde al PIB per cápita de los estados (vecinos) que integran la región correspondiente y el eje de las X al PIB per cápita del estado. Los estados ubicados en el cuadrante superior derecho son considerados como entidades favorecidas de acuerdo con nuestra clasificación; a las que se ubicaron en el cuadrante superior izquierdo e inferior derecho se les señala como entidades poco favorecidas y, por ultimo, a aquellas ubicadas en el cuadrante inferior derecho se les cataloga como entidades federativas estancadas. 
Cuadro 4. Clasificación de entidades federativas de acuerdo a impactos del TLCAN

\begin{tabular}{|c|c|c|}
\hline I & II & III \\
FAVORECIDAS & POCO FAVORECIDAS & ESTANCADAS \\
\hline Chihuahua & Sonora & Baja California \\
\hline Coahuila & Nayarit & Baja California Sur \\
\hline Nuevo León & Jalisco & Sinaloa \\
\hline Tamaulipas & Colima & Distrito Federal \\
\hline Durango & Michoacán & Hidalgo \\
\hline Zacatecas & Guanajuato & Morelos \\
\hline San Luis Potosí & Querétaro & Oaxaca \\
\hline Aguascalientes & Puebla & Chiapas \\
\hline & Tlaxcala & Veracruz \\
\hline & Yucatán & Tabasco \\
\hline & & Campeche \\
\hline & & Quintana Roo \\
\hline
\end{tabular}

Fuente. Elaboración propia.

Las entidades federativas del grupo I corresponden a aquellas que presentan un crecimiento en base a un mayor dinamismo de los sectores secundarios y terciarios y un aprovechamiento de ventajas asociadas a sectores primarios junto con el desarrollo de industrias manufactureras. El segundo grupo se caracteriza por presentar entidades con un estancamiento o bajo crecimiento de sus actividades industriales y terciarias y permanencia de actividades primarias de baja productividad (agricultura tradicional o explotación minera en decadencia); en este grupo algunos estados se caracterizan por fuertes procesos de desindustrialización como efecto de la baja competitividad de viejas actividades manufactureras; en este grupo destaca Jalisco, donde, no obstante contener a la segunda metrópoli de importancia para el país por el número de población, el peso del sector secundario ha decaído sin reponer actividades nuevas que deberían aprovechar las ventajas del importante sector agroindustrial. El tercer grupo se caracteriza por incluir entidades con una fuerte incidencia de sectores primarios de lento crecimiento o francamente en contracción, otras con pérdida de dinamismo de sectores industriales y/o de algunos sectores terciarios y un lento crecimiento en su PIB per cápita derivado de niveles altos de emigración acentuada en los últimos años y una baja expansión de las actividades económicas; la presencia del Distrito Federal en este grupo se debe básicamente al proceso de desindustrialización que viene experimentado desde antes del TLCAN.

Al observar el mapa 2 se reafirma la idea principal del presente artículo, que señala que con el TLCAN y la acentuación de la apertura comercial, en México se mantiene una polarización territorial y se incrementan asimetrías regionales entre el norte y el sur del país.

\section{Consideraciones finales}

Los desequilibrios regionales que se presentan al interior de México son resultado de procesos acumulados a lo largo del tiempo, mismos que se han acentuado a partir del modelo de apertura comercial y la puesta en operación del TLCAN. Estos desequilibrios son producto tanto de decisiones endógenas como exógenas que afectan en sentido positivo o negativo al territorio, las cuales finalmente expresan los procesos derivados de la política económica interna.

En el primer caso, durante el largo periodo conocido como desarrollo estabilizador, la inversión controlada por una economía estatizada se concentró en las principales ciudades, o bien se canalizó hacia macroproyectos sectoriales de infraestructura que generaron limitados procesos de crecimiento 
Mapa 2. Clasificación de entidades federativas de acuerdo a impactos del TLCAN

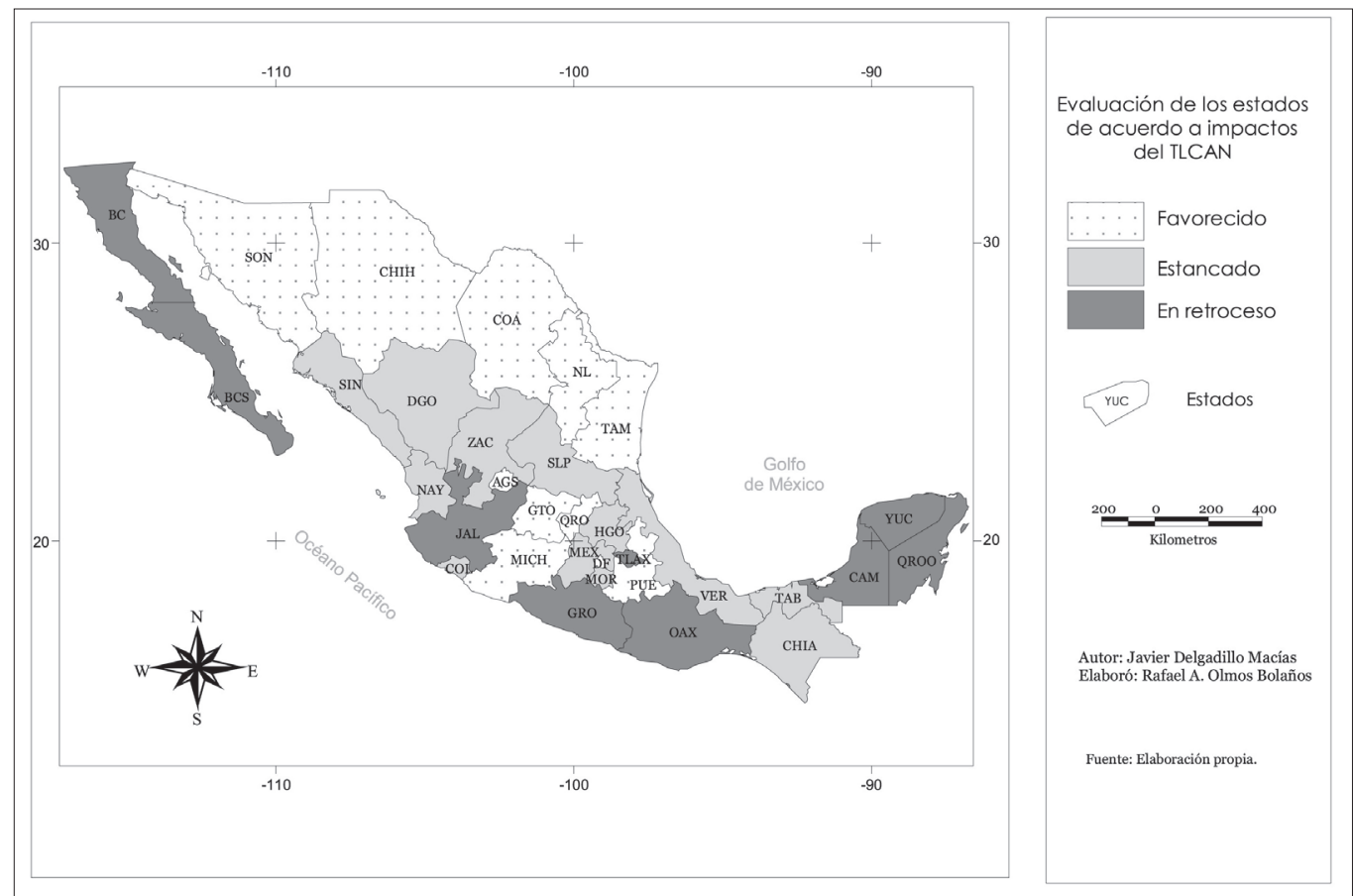

Fuente. Elaboración propia con base en los resultados del Índice de Moran y el modelo de Convergencia Condicional aplicados en el estudio.

sostenido del entorno territorial y poca capacidad de traducir ese crecimiento en bienestar social. Se favoreció la concentración territorial en pocos lugares y se acentuó el desequilibrio entre regiones, estados y ciudades. Se hicieron notorios problemas sociales como la pobreza y comenzó el abandono de zonas rurales antes productivas. Los programas de impulso industrial indujeron en las ciudades mecanismos de atracción que operaron en el mismo sentido: se concentró la inversión y población y se desalentó el crecimiento de las regiones más pobres; la macrocefalia urbana se hizo presente y se manifestó la crisis del sector agropecuario medida como desbalance notable respecto de los otros sectores productivos.

Las decisiones de inversión vinculadas a la política económica interna consolidaron las regiones que ya presentaban ventajas en términos de dotación inicial de capital, y se les complementó con obras de infraestructura que les hizo ganar una clara delantera con respecto al resto de las regiones. Las regiones del Sur apenas si jugaron un papel marginal como proveedoras de materias primas. El Centro y el Norte se industrializaron, desarrollaron infraestructura para la atracción de capital productivo, principalmente mediante la inversión extranjera directa y con alto componente tecnológico, y sentaron las bases de los nuevos procesos que posteriormente vendrían con la apertura comercial.

La globalización y el TLCAN fueron coincidentes con la implementación del modelo neoliberal; se acentuó la desigual estructura regional que ya persistía y creció la polarización social. Se define un claro esquema de regiones que avanzan a ritmos y condiciones propias de los tiempos actuales, y otras estancadas o en pleno retroceso derivado del desfase tecnológico, del declive de su planta productiva y de la ausencia de políticas adecuadas de incentivación de sistemas productivos locales y cadenas de valor. También se reconoce que con el TLCAN las exportaciones mexicanas crecieron de manera relevante, pero los efectos benéficos de equilibrar crecimiento con desarrollo social y generación de mayor empleo no llegaron. Las asimetrías regionales entre los estados del Norte y 
Centro respecto de los ubicados en el Sur también se acentuaron. En el nivel metropolitano, las ciudades ensancharon las diferencias de concentración entre aquellas zonas urbanas que históricamente han sido los ejes del crecimiento económico regional (Ciudad de México, Monterrey y Guadalajara); se consolidaron otras ciudades de segundo nivel en la franja fronteriza y el altiplano mexicano; las ciudades medias y pequeñas se duplicaron en número en los últimos 25 años. Sin embargo, se acentuó la polarización dentro del sistema urbano nacional y se despobló el México rural.

El México de hoy se divide en tres porciones: 8 estados favorecidos durante el periodo del TLCAN; 10 poco favorecidos; 14 estados en condiciones de estancamiento. Sus dinámicas económicas son excluyentes y contrapuestas en términos de intereses regionales.

Finalmente, una conclusión del trabajo nos lleva a considerar que la estrategia de desarrollo regional del país debe ser contemplada en dos dimensiones posiblemente convergentes: las dinámicas mundiales y el desarrollo regional. El reto consiste en impulsar mecanismos de complementariedad territorial sobre una base prominentemente de desarrollo endógeno, para lo cual se propone incorporar procesos que reanimen las ventajas locales de las regiones desfavorecidas; se impulsen acciones de política regional competitiva; se incorporen prácticas de compensación económica y asociatividad productiva; se prioricen actividades de capacitación y se estimule la inducción local de inversiones en ciencia y tecnología; y, sobre todo, se promuevan políticas decididas que contrarresten la declinación progresiva de las regiones.

\section{Referencias bibliográficas}

Aguayo, S. (2006). Income divergence between Mexican States in the 1990s: the role of skill premium. En T. R. Leinbach, Growth and Change, a Journal of Urban and Regional Policy, 37.

Aguilar, A. (2002). Globalización y capitalismo. México: Plaza y Janés.

Aguilar, I. (1995). Monterrey: formas de integración a la economía del sur de Estados Unidos. Comercio Exterior, 45, 5.
Alba, F. (2002). México: un dificil cruce de caminos. Recuperado el 21 de noviembre de 2007, de http://www.migrationinformation.org/Profiles/display.cfm?id=204.

Alburquerque, F. (2004). Desarrollo económico local y descentralización en América Latina. Revista de la CEPAL, 82.

Alegría, T. (2000). Juntos pero no revueltos: ciudades en la frontera México-Estados Unidos. Revista Mexicana de Sociología, 62, 2.

Amin, S. (1999). El capitalismo en la era de la globalización. España: Paidos.

Armstrong, H. \& Taylor, J. (2000). Regional economics and policy. London: Basil Blackwell.

Arroyo, F. (2001). Dinámica del PIB de las entidades federativas en México, 1980-1999. Comercio Exterior, 51, 7.

Audley, J., Polaski S. \& Papademetriou, D. (2003). NAFTA's promise and reality: lessons from Mexico for the hemisphere. Recuperado el 17 de octubre de 2007, de http://www.ceip.org/files/ publications/NAFTA_Report_full.asp.

Baigorri, A. \& Cortés, G. (1997). Un nuevo desafío en el análisis regional: las ciudades y regiones fronterizas. Ponencia presentada en la XXIII Reunión Española de Estudios Regionales, Valencia, España.

Banco Mundial (2003). Lessons from NAFTA for Latin America and the caribbean countries: a summary of research findings. Washington D.C.: Autor.

Barro, R. \& Sala i Martín, X. (2004). Economic growth. (2nd ed.). Cambridge, Massachusetts: The MIT Press.

Bassols, Á. (1999). Investigaciones urbanas y regionales de México: ¿para conocer o transformar una realidad? En H. Muñoz (Coord.), La sociedad mexicana frente al tercer milenio. México: Miguel Ángel Porrúa-Coordinación de Humanidades, UNAM,

Becattini, G. (2000). Dal distretto industriale allo sviluppo locale. Torino: Bollati Boringhieri.

Bendavid-Val, A. (2001). Análisis económico regional y local para profesionales. Sevilla: Instituto de Desarrollo Regional.

Benko, G. \& Lipietz, A. (eds.) (2000). La richesse des régions: la nouvelle géographie socio-économique. París: Presses Universitaires de France. 
Bervejillo, F. (1995). Territorios de la globalización. Nuevos procesos y estrategias de desarrollo. Revista Prisma, 4.

Boisier, S. (2000). Conversaciones sociales y desarrollo regional. Potenciación del capital sinergético y creación de sinergía cognitiva en una región. Talca: Universidad de Talca.

Bremen, S. et. al (2004). Clusters and industrial districts. Interdisciplinary Review, Sandusky's Colossus, Little Rock.

Calva, J. L. (2005). México: la estrategia macroeconómica 2001-2006. Promesas, resultados y perspectivas. Problemas del Desarrollo, Revista Latinoamericana de Economía, 36, 143.

Capello, R. (2006). La economía regional tras cincuenta años: Desarrollos teóricos recientes y desafíos futuros. Investigaciones Regionales, 9, 171-194.

Caravaca, I. (1998). Los nuevos espacios emergentes. Revista de Estudios Regionales, 50.

Carmona, F. (1999). En busca de alternativas para México en la Globalización. Revista Aportes, 12.

Carrillo, M. (2001). La teoría neoclásica de la convergencia y la realidad del desarrollo regional en México. Problemas del Desarrollo, Revista Latinoamericana de Economía, 32, 27.

Castells, M. (2000). La sociedad red. Madrid: Alianza Editorial.

Chamboux-Leroux, J. I. (2001). Efectos de la apertura comercial en las regiones y la localización industrial en México. Comercio Exterior, 51, 7.

Chang, H. J. (2003). Globalization, economic development and the role of the State. London: Zed Books.

Chomsky, N. \& Dieterich, H. (1999). La sociedad global. Educación, mercado y democracia. México: Joaquín Mortiz-Planeta Mexicana.

Corona., M. Á. (2003). Efectos de la globalización en la distribución espacial de las actividades económicas. Comercio Exterior, 53, 1.

Corporación Andina de Fomento (2005). América Latina en el comercio global: ganando mercados. Caracas, Venezuela: Autor

Cortina, J., De la Garza, R. \& Ochoa, E. (2005). Remesas: límites al optimismo. Foreign Affairs en Español, 5, 3.
De María y Campos, M. (2001). Globalización y desarrollo desigual internacional: su impacto en la cohesión social en México. En M. De María y Campos y G. Sánchez (Eds.), ¿Estamos unidos mexicanos? Los límites de la cohesión social en México. México: Editorial Planeta Mexicana.

De Mattos, C., Figueroa, O., Jiménez, R., Orellana, A. \& Yánez G. (Eds.) (2005). Gobernanza, competitividad y redes. Santiago: Instituto de Estudios Urbanos y Territoriales, Pontificia Universidad Católica de Chile.

Delgadillo, J. \& Torres, F. (2006). México. Más liberalismo, menos territorio: transformaciones regionales a la luz de la globalización. Cadernos PROLAM/USP-Brazilian Journal of Latin American Studies, 1, 8.

Delgadillo, J., Torres, F. \& Gasca, J. (2001). El desarrollo regional de México en el vértice de dos milenios. México: Miguel Ángel PorrúaIIEc-UNAM.

Dussel, E. (2000). La inversión extranjera en México. Revista de la CEPAL-ECLAC, Serie Desarrollo Productivo, 80.

Dussel, E., Galindo L. M. \& Lona, E. (Coord.) (2003). Condiciones y efectos de la inversión extranjera directa y del proceso de integración regional en México durante los noventa. Una perspectiva macro, meso y micro. México: Facultad de Economía-UNAM, BID-INTAL y Plaza y Valdés.

Elizondo, C. (2006, noviembre). Instituciones, competencia y desigualdad: tres caras de un mismo problema. Ponencia presentada en la Conferencia Internacional Equidad y Competencia para un Alto Crecimiento en México. Ciudad de México: Banco Mundial y Centro David Rockefeller de Estudios Latinoamericanos de la Universidad de Harvard.

Esquivel, G. (1999). Convergencia regional en México. El Trimestre Económico, 56.

Esser, K., Hillebrand, W., Messner, D. \& MeyerStamer, J. (1996). Systemic competitiveness: new governance patterns for industrial development. London: Frank Cass.

Federal Reserve Bank of Dallas (2005). Diferencias cíclicas surgen en las economias de las ciudades fronterizas. Recuperado el 8 de diciembre de 
2007, de http://www.dallasfed.org/entrada/articles/2005/sp_cross0501b.html.

Fernández, A. (1994). La regionalización de la economía mexicana y el Tratado de Libre Comercio de América del Norte: reformas económicas y el sistema político. Revista de Economía y Trabajo, 4.

Ferrer, A. (1996). Historia de la globalización. Orígenes del orden económico mundial. México: Fondo de Cultura Económica.

García Canclini, N. (2000). La globalización imaginada. México: Paidós.

Garza, G. (Coord.) (2006). La organización espacial del sector servicios en México. México: El Colegio de México.

Gasca, J. (2000). Espacios trasnacionales. Interacción, integración y fragmentación en la frontera México-Estados Unidos. México: Instituto de Investigaciones Económicas-UNAM-Miguel Ángel Porrúa.

Gatto, F. (1999). Globalización y regiones. La construcción de ventajas competitivas localmente específicas. En Centro Latinoamericano de Economía Humana (Ed.), Desarrollo local en la globalización. Montevideo: CLAEH.

Gereffi, D. \& Bair, J. (2002). Free trade and uneven development: the north american apparel industry after NAFTA. Philadelphia: Temple University Press.

González, C. (1995). Los senderos de la integración: experiencias de España y México. Comercio Exterior, 45, 2.

Gruben, W.C. (2001). Was NAFTA behind Mexico's high maquiladora growth? Economic and Financial Review, Federal Reserve Bank of Dallas, Texas. Recuperado el 11 de noviembre de 2007, de http://www.dallasfed.org/research/efr/index.html

Haber, S. (2006, noviembre). Why banks don't lend: the mexican financial system. Ponencia presentada en la Conferencia Internacional Equidad y competencia para un alto crecimiento en México. Ciudad de México: Banco Mundial y Centro David Rockefeller de Estudios Latinoamericanos de la Universidad de Harvard.

Helmsing, A. H. J. (2002). Perspectivas sobre el desarrollo económico localizado. EURE, 28,84 .
Hildenbrand, A. (2006). Las redes de cooperación entre ciudades: la experiencia europea. En A. Tarroja \& R. Camagni (Coords.), Una nueva cultura del territorio. Criterios sociales y ambientales en las políticas y el gobierno del territorio. Barcelona: Diputación de Barcelona.

Iani, O. (1999). La era del globalismo. México: Siglo Veintiuno Editores.

Katz, I. (2000). Impacto regional del TLCAN. Un análisis de la industria manufacturera. En B. Leycegui \& R. Fernández de Castro (Coords.), ¿Socios Naturales?: cinco años del TLCAN. México: ITAM-Miguel Angel Porrúa.

Kitson, M., Martín, R. \& Tayler, P. (2005). The regional competitiveness debate. Mimeo, Cambridge, UK.

Knox, P. L. (1996). Globalization and the world city hypothesis. Scottish Geographical Magazine, 112, 2.

Kose, M., Ayhan, M., Guy, M. \& Towe, C.M. (2004). How has NAFTA affected the Mexican economy? Review and evidence. Recuperado el 14 de diciembre de 2007, de http:www.springerlink.com/content/ qt $2 \mathrm{mu} 4 /$ ?p $=7 \mathrm{c} 941$ eece $6 \mathrm{ca} 4 \mathrm{~d} 95 \mathrm{a} 5 \mathrm{fd} 1 \mathrm{c} 6$ 3860c646f\&pi=0

Krugman, P. (2003). The great unraveling. Losing our way in the new Century. Massachusetts: The MIT Press.

Leycegui, B. (2000). Acordar para disentir: la solución de controversias en el Tratado de Libre Comercio de América del Norte. En B. Leycegui \& R. Fernández (Coords.), ¿Socios Naturales?: cinco años del TLCAN. México: ITAM-Miguel Angel Porrúa.

Lozano F. (2002). La migración mexicana, su historia e impacto. En Sistema Económico Latinoamericano y del Caribe (Ed.), Las migraciones internacionales en América Latina y el Caribe, Edición mayo-agosto.

Maddison, A. (2001). The world economy. A millennial perspective. Paris: Development Center Estudies, OECD.

Méndez, R. (2006, octubre). Difusión de innovaciones en sistemas productivos locales y desarrollo territorial. Ponencia Invitada en el Tercer Congreso Internacional de la Red SIAL Alimentación y Territorio, Baeza, España. 
Messmacher, M. (2000). Desigualdad Regional en México. El efecto del TLCAN y otras reformas estructurales. Recuperado el 28 de octubre de 2007, de http://www.nobe-ref.org/pdf/Conferences/2001/panelii_mmessmacher.pdf.

Molero, J. (2001). Innovación tecnológica y competitividad en Europa. Madrid: Ed. Síntesis.

Mortimore, M., Buitelaar R. \& Bonifaz, J. L. (2000). México: un análisis de su competitividad internacional. Santiago: Red de Inversiones y Estrategias Empresariales de la CEPAL.

NAFTA Secretariat (2006). North american free trade agreement (legal text). Recuperado el $7 \mathrm{de}$ noviembre de 2007, de http://www.nafta-secalena.org/DefaultSite/index_e.aspx.

Novelo, F. (2006). Situación actual y perspectivas de la migración México-Estados Unidos. Observatorio de la Economía Latinoamericana, Revista Académica de Economía. Recuperado el 10 de diciembre de 2007, de http://www. eumed.net/cursecon/ecolat/mx/.

OECD (2006). Competitive cities in the global economy. Paris: OECD-Territorial Review.

Ohmae, K. (1990). The borderless world: power and strategy in the interlinked world. Londres: Harper \& Collins.

Ornelas, J. (2004). Impacto de la globalización económica neoliberal en el ordenamiento urbano y territorial. Papeles de Población, 41.

Ortiz, L., Vázquez, F. A. \& Díaz, L. M. (1998). Aspectos jurídicos del Tratado de Libre Comercio de América del Norte y sus acuerdos paralelos (2a. Ed.). México: Themis, Colección Ensayos Jurídicos.

Papademetriou, D. (2003). El cambio de expectativas en el libre comercio y migración. En $\mathrm{La}$ promesa y la realidad del TLCAN. Washington, D. C.: Carnegie Endowment for International Peace.

Patiño, R. (1993). Acceso a mercados. En J. Witker (Coord.), El Tratado de Libre Comercio de América del Norte. Análisis, diagnóstico y propuestas jurídicas. México: Instituto de Investigaciones Jurídicas-UNAM.

Perry, G.E, López, J.H., Maloney, W.F., Arias, O. \& Servén, L. (2006). Poverty, reduction and growth: virtuous and vicious circles. Washington, D. C.:The World Bank.
Polèse M. \& Pérez, S. (1992). La integración económica norteamericana y cambio regional en México. Comercio Exterior, 45, 2.

Pose, A. (2002). The impact of trade liberalization on regional disparities in Mexico. Growth and Change, a Journal of Urban and Regional Policy, 33.

Ray, Debraj (2002). Economía del Desarrollo. Barcelona: Antoni Bosch.

Reinoso, E. (1995). La competitividad de los estados mexicanos. México: Centro de Estudios Estratégicos del Instituto Tecnológico de Estudios Superiores Monterrey.

Rivera, M. A. \& Caballero, R. (2003). Los sistemas de innovación nacionales y la teoría del desarrollo. Problemas del Desarrollo, 34, 134.

Robinson, M. (1998). Methods and techniques in Human Geography. England: West Sussex.

Romero, J. \& Puyana, A. (2004). Evaluación integral de los impactos e instrumentos del capitulo agropecuario del TLCAN. México: Secretaría de Economía.

Rosas, M.C. (2000). México y Canadá ante los procesos de la globalización y regionalización. En G. Ibarra \& A.L. Ruelas (Coods.), México y Canadá ante los procesos de la Globalización. Fronteras tensionadas en América del Norte. México: Universidad Autónoma de SinaloaGrupo Editorial Porrúa.

Rosselet-McCauley S. (2003). Methodology and principles of analysis. IMD World Competitiveness Yearbook.

Rózga, R. (1994). La polarización espacial en las teorías del desarrollo regional. Revista Gestión y Política, 111, 1.

Rubio, L. (1992). ¿Cómo va a afectar a México el Tratado de Libre Comercio? México: Fondo de Cultura Económica.

Ruijter, A. (1997). The era of glocalization. En T. Van Naerssen, N. Rutten \& A. Zoomers (Eds.), The diversity of development. Assen, Van Gorkum.

Ruiz, C. (2004). Dimensión territorial del desarrollo económico de México. México: Facultad de Economía, UNAM.

Ruiz, R. (2002). Política económica de la competitividad. El Mercado de Valores, 12. 
Santos, M. (2000). La naturaleza del espacio. Técnica y tiempo. Razón y emoción. Barcelona: Editorial Ariel.

Sassen, S. (2003). Globalization or denationalization? Review of International Political Economy, $10,1$.

Schettino, M. (1994). TLC Tratado de Libre Comercio ¿Qué es y cómo nos afecta? México: Grupo Editorial Iberoamérica.

Schneider, J. (2000). El TLC y el transporte: impactos en la frontera México-Estados Unidos. Borderline, 8, 5.

Scott, J. A. et al (2002). Global city-regions. Los Ángeles: School of Public Policy and Social Research.

Secretaría de Economía (2007). Acuerdos y negociaciones comerciales de México con el mundo. (Información al mes de enero de 2007). México: Subsecretaría de Negociaciones Comerciales Internacionales.

Silva, I. (2003). Disparidades, competitividad territorial y desarrollo local y regional en América Latina. Revista del ILPES-CEPAL, Serie Gestión Pública, 33.

Simmies, J. (1997). Innovation, networks and learning regions? Regional Policy and Development, 18.
Torres, F. (2005). El atraso regional en los procesos globales: la región del Plan Puebla-Panamá. Problemas del Desarrollo. Revista Latinoamericana de Economía, 36, 142.

Trápaga, Y. (2003, junio). Las tendencias de la integración económica regional y sus impactos en México. Ponencia presentada en el XIII Seminario de Economía Urbana y Regional, Instituto de Investigaciones EconómicasUNAM, México.

Valdivia, M. (2007). Análisis de convergencia espacial en México a partir de remesas internacionales e inversión extranjera directa. Documento de Trabajo, Programa de Estudios Regionales, CRIM/UNAM, México.

Vázquez, A. (2005). Las nuevas fuerzas del desarrollo. Barcelona: Antoni Bosch.

Villarreal, R. \& Ramos, R. (2002). México competitivo 2020. Un modelo de competitividad sistémica para el desarrollo. México: Editorial Océano.

Wong, P. (1997). Integración de América del Norte: implicaciones para la competitividad y competencia internacional de las regiones. Cuadernos de la CEPAL-ILPES, Dirección de Politicas y Planificación Regionales, 97, 17. 